\title{
REFLEXIONES PARA AVANZAR EN LOS ESTUDIOS DEL PERÍODO ARCAICO EN LOS ANDES CENTRO-SUR ${ }^{1}$
}

\author{
THOUGHTS ON MOVING FORWARD OF THE STUDY OF THE ARCHAIC \\ PERIOD IN THE SOUTH-CENTRAL ANDES
}

\author{
Mark S. Aldenderfer ${ }^{2}$ y Luis Flores Blanco ${ }^{3}$
}

\begin{abstract}
Los autores identifican los problemas de investigación del Período Arcaico (10.000-3.400 a.p.) en la zona Centro-Sur de los Andes, para sugerir las prioridades que se deben tomar en cuenta para la realización de futuros estudios arqueológicos en la región. Varios temas arqueológicos aún permanecen inconclusos: (1) Los orígenes de los primeros habitantes de los Andes Centro-Sur. ¿Por dónde llegaron, en qué condiciones climáticas, cuál fue la cultura material que aportaron y cómo se dio el paso hacia el período Arcaico? (2) ¿Qué se conoce del tiempo arcaico en los flancos orientales de los Andes? (3) ¿Dónde se observa el Arcaico boliviano y cuáles son sus características? (4) ¿Cuál fue la adaptación del Arcaico en la zona peruana del Lago Titicaca? (5) ¿Cuál es el estado de la cronología regional que hemos construido para el Arcaico? ¿Qué estudios se han hecho y cuánto falta por hacer? Por último, concluimos con una discusión de tres aspectos principales del proceso cultural de la región: (a) las adaptaciones de los primeros habitantes de la región, (b) el proceso de domesticación del ganado y la cultivación agrícola, y (c) el inicio y origen del desarrollo de la sociedad compleja y la jerarquía social.
\end{abstract}

Palabras claves: Andes Centro-Sur, Arcaico, lítico, paleoclima, domesticación, complejidad.

The authors identify a number of outstanding research questions about the Archaic Period (10,000-4,300 BP) and based upon these, make a number of suggestions about the conduct of future research in the region. These research questions include: (1) when did people first enter the south-central Andes, what were the climatic conditions at that time, and what characterized the transition to the Archaic? (2) What do we know of the Archaic on the eastern flanks of the Andes? (3) Where is the Archaic in Bolivia? (4) What was the nature of the Archaic adaptation along the Peruvian side of Lake Titicaca? and (5) what is the status of our efforts to build a sound regional chronology for the Archaic? We conclude with a discussion of three aspects of culture process in the region: (a) adaptations of the earliest inhabitants of the region, (b) the process of animal domestication and food production, and (c) the origins of complexity.

Key words: South-Central Andes, Archaic, lithic, paleoclimate, domestication, complexity.

El estudio arqueológico de los tiempos tempranos conocido como el periodo Arcaico (anteriormente llamado Precerámico) en los Andes Centro-Sur tiene una trayectoria de trabajo que abarca casi un siglo, originándose desde los pioneros estudios de Uhle $(1919,1922)$. Sin embargo, desde hace relativamente poco tiempo los arqueólogos han adquirido una comprensión más matizada de la diversidad y complejidad del periodo Arcaico en esta región. En este esfuerzo investigativo arqueólogos peruanos, chilenos, bolivianos y argentinos, tanto como norteamericanos y europeos, han contribuido significativamente a este logro; muchos de ellos son parte de este número.
Durante las últimas dos décadas en particular se ha dado a conocer información muy relevante sobre el Arcaico en la región; la mayor parte proviene de investigaciones en la costa de los actuales territorios del sur del Perú y extremo norte de Chile (Lavallée et al. 1999a, 1999b; Muñoz et al. 1993; Sandweiss 2003; Standen et al. 2004; Wise 1997, 1999), así como la sierra occidental de ambos países (Aldenderfer 1998; Núñez y Santoro 1988).

Existen localidades de los Andes Centro-Sur cuya arqueología del período Arcaico ha sido poco investigada, por ejemplo, en la cuenca del Lago Titicaca faltan excavaciones más intensivas, aunque durante los últimos quince años se han realizado

$1 \quad$ Este trabajo se realizó en el contexto de la publicación de los manuscritos presentados en el Simposio "El periodo Arcaico en los Andes Surcentrales: Tradiciones Culturales e Innovaciones Tecnológicas," como parte del $53^{\circ}$ Congreso Internacional de Americanistas, llevado a cabo en México en julio 2009 y publicados en este número.

2 University of California Merced, School of Social Sciences, Humanities and Arts, Merced, CA, USA, 95343. maldenderfer@ucmerced.edu

3 Universidad Nacional Mayor de San Marcos, Lima, Perú. 1flores78@gmail.com 
prospecciones sistemáticas en el lado peruano de la cuenca, en el valle de Ilave (Aldenderfer 2002, 2011; Craig 2005, 2011; Klink 2005). Por tanto, el estudio del Arcaico es un tema que debe desarrollarse mejor por el lado boliviano, más allá de los esfuerzos aislados (como los informes que se presentan en este número).

En el noroeste argentino aún falta un esfuerzo de síntesis para entender el periodo Arcaico de manera global (Salomón Hocsman, comunicación personal 2011); sin embargo, algunos estudios recientes con este fin están disponibles (Aschero y Hocsman, en este número; Martínez 2010). Nosotros mismos somos conscientes que no hemos realizado una revisión minuciosa de esta región.

Pero tal vez el mayor problema que se observa para esta región es que todos los estudios, datos e información están guardados dentro de las fronteras políticas de cada país y es necesario compartir y discutirlos. Este objetivo motivó la realización del Simposio "El periodo Arcaico en los Andes Surcentrales: Tradiciones Culturales e Innovaciones Tecnológicas," como parte del 53 Congreso Internacional de Americanistas, llevado a cabo en México en julio 2009.

En este informe se discutirán los datos que se conocen sobre el período Arcaico en los Andes Centro-Sur, y se identificará qué es lo que aporta la publicación de este número a ese objetivo, pero dándole un matiz distinto -no sólo un balance, que ya otros colegas han logrado con gran poder de síntesis (Aldenderfer 1989, 2009; Muscio 2001; Núñez y Santoro 1988; Sandweiss 2003; Standen et al. 2004)- sino además elaborar una agenda con una serie de tareas que nos falta terminar o que, incluso, aún no las hemos empezado. Es decir, dirigir nuestra atención a temas que ya deberíamos sacar de la sombra, iluminándolos con nuevos datos, si es que deseamos una visión amplia del desarrollo social y cultural de la región durante el periodo Arcaico.

\section{Los Andes Centro-Sur}

La zona Centro-Sur de los Andes cubre los territorios, por el norte del extremo sur del Perú, desde los valles del Río Camaná/Majes en Arequipa; hacia el sur, el Norte Grande de Chile, que comprende las regiones de Arica, Parinacota, Tarapacá y Antofagasta; el altiplano peruano-boliviano, donde destaca la meseta del Collao, pero también la sierra central y valles bolivianos; el noroeste argentino, que abarca las provincias de Jujuy, Salta, Tucumán, Catamarca, La Rioja y Santiago del Estero. La región está compuesta de costas, valles, quebradas, sierras subandinas, punas y sierras orientales, que han sido agrupadas en cinco subregiones: los valles occidentales, el circumtiticaca, el altiplano meridional, la circumpuneña y el valluna (Aldenderfer 1989). Fue en este territorio que los primeros habitantes se establecieron, hasta donde conocemos, entre los 12.000 a 13.000 años a.p. (Figura 1).

Pero los Andes Centro-Sur no siempre tuvieron la geografía que hoy conocemos; ha pasado por varios cambios desde finales del Pleistoceno y durante todo el Holoceno. Esta historia paleoambiental se ha prestado para varias interpretaciones sobre el devenir del hombre en el escenario (Aldenderfer 2009; Craig, en este número; Núñez et al. 2002; Yacobaccio 2003).

Actualmente existe un gran número de investigaciones como para tener una visión más general de la evolución paleoambiental de los Andes Centro-Sur, sobre todo de las tierras altas. Se puede decir que el intervalo entre los 11.000 y 8.400 a.p. se caracterizó por una humedad mayor que la actual (Grosjean et al. 2003; Latorre et al. 2005; León 2007:44; Olivera et al. 2006). Esto abarcó la transición del Pleistoceno Tardío al Holoceno Temprano, probablemente fue un ambiente más homogéneo, con extensión de pastizales de altura que pudieron alimentar fauna ahora extinta (caballo americano, megaterios, entre otros) (Yacobaccio 2003).

Por ejemplo, la característica dominante del altiplano peruano-boliviano fue la presencia de dos grandes lagos: el antiguo Titicaca al norte (con aproximadamente $8 \mathrm{~m}$ de altura sobre su nivel actual) y el denominado lago Pocuyo, que cubría la actual cuenca del lago Poopó y los salares de Uyuni y Coipasa con una elevación de ca. 3.765 m (Argollo y Mourguiart 2000:43). Este tipo de ambiente húmedo también se ha reportado en la zona costera, como lo demuestran capas extensivas de sedimentos que son productos de lluvias torrenciales y la presencia de mega Niños (Lavallée et al 1999b:395; Keefer et al. 1998; Usselmann et al. 1999). Incluso en Atacama, el desierto más árido del planeta, se plantea un período climático más benigno (Quade et al. 2008).

Un período de desecación comenzó alrededor de 8.500 años a.p., con un aumento de la temperatura llegando a ser extrema por los 6.000 años. Es 


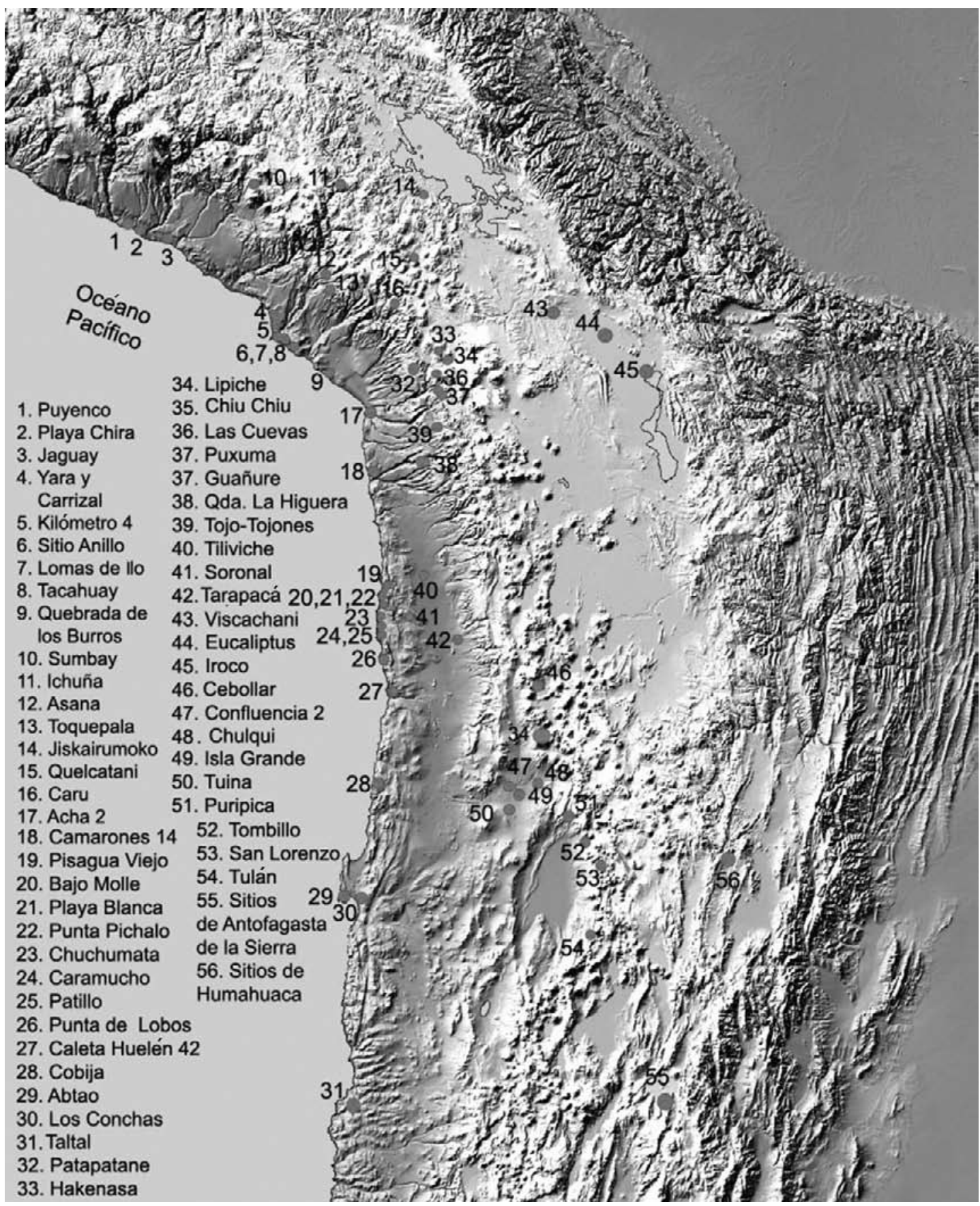

Figura 1. Mapa de distribución de sitios del periodo Arcaico en los Andes Centro-Sur.

Distribution map of Archaic Period sites in the South Central Andes.

durante este intervalo que el ambiente se fragmenta. El calentamiento y la sequedad habrían producido incendios, mientras el paisaje se cubría de gramíneas y queñuales (Craig et al. 2009), adquiriendo una fisonomía de desierto de altura (Yacobaccio 2003).
Por ejemplo, el nivel del Lago Titicaca llegó hasta $100 \mathrm{~m}$ debajo del nivel actual, ocurriendo el nivel más bajo alrededor de los 5.300 a.p. (Cross et al. 2000). Esta aridez es consistente con las evidencias en otras partes del sur de Sudamérica, incluyendo 
el altiplano y la costa de Chile, la puna del noroeste argentino e incluso la Amazonia central (Cross et al. 2000; Olivera et al. 2006).

Este fenómeno ambiental de aridez habría inspirado a plantear un "silencio arqueológico", un "hiato" en la ocupación de los valles altos y las punas de los Andes del norte de Chile (Núñez y Grosjean 1994, Núñez et al. 1997; Núñez y Santoro 1988), un fenómeno que habría empujado a las poblaciones puneñas a migrar hacia la costa (Núñez y Santoro 1988). No obstante, durante los siguientes años reportes de nuevos sitios del Arcaico Medio (Puripica-3, Tulán-67) y otros asentamientos ubicados en orillas lacustres (Laguna Miscanti y Salar Huasco) (Núñez et al. 1999; Núñez et al. 2002) permitieron sostener que las pocas poblaciones que decidieron quedarse en las serranías se aglomeraron en torno a "ecorrefugios" (Núñez et al. 1999).

Sin embargo, el registro paleoambiental y arqueológico de otras regiones pone en duda que el fenómeno de aridez y el silencio arqueológico puedan ser un modelo que se pueda generalizar en los Andes Centro-Sur. Al contrario, evidencias de un Holoceno con episodios húmedos, que interrumpieron las fases áridas, se vienen sosteniendo para otras regiones, como la cuenca del Titicaca y otras localidades (Baker et al. 2001; Thompson et al. 1998) tanto como en el norte de Chile (Betancourt et al. 2000; Latorre et al. 2002; Rech et al. 2002).

Datos arqueológicos de otras regiones de los Andes occidentales y del altiplano peruano también demuestran diferencias, revelando una ocupación significativa durante esos tiempos (Aldenderfer 1998, 2009, 2011). Incluso Antofagasta de la Sierra del norte argentino -que también se vio afectada por este período de sequedad (Olivera et al. 2006), considerada por algunos como un ecorrefugio (Núñez et al. 1999; Olivera y Tchilinguirian 2006)- contó con recursos suficientes para sustentar una población, tal vez con tiempos más largos de permanencia en la región (Martínez 2010).

Lo que sí parece claro es que en la costa, durante este tiempo se venían dando cambios importantes en su patrón de asentamiento, en particular estancias más permanentes en sitios como Quebrada de los Burros (Carré et al. 2009; Lavallée et al. en este número) o en la formación de conchales espesos de más de $4 \mathrm{~m}$ de profundidad como en Pisagua y Camarones (Standen et al. 2004).

Estas evidencias contrarias han puesto en debate el "silencio", lo que significaría que este fenómeno habría estado circunscrito a territorios más áridos y mayormente aquellos ubicados al sur del paralelo $20^{\circ} \mathrm{S}$ (Núñez et al. 2002:824). De esta manera, el impacto de la sequía fue variable en los Andes Centro-Sur, así como diversas debieron ser las estrategias económicas asumidas por las poblaciones de estas localidades.

A partir de los 5.000 a.p. (Holoceno Tardío) hubo un aumento de precipitación y de humedad hasta llegar a un pico ca. 4.000 años a.p. (Abbott et al. 1997; Baker et al. 2005; Baker et al. 2001; Cross et al. 2000), creándose un ambiente con mayor presencia arbórea (Craig et al. 2009) hasta lograr, en varios cientos de años, un ambiente moderno de puna. Pero no en todos lados se dio al mismo tiempo. Por ejemplo, se ha propuesto que al norte de la cuenca del Titicaca se alcanzaron condiciones húmedas prematuramente, antes del altiplano boliviano (Abbott et al. 2003).

Por supuesto, los arqueólogos ahora tienen más instrumentos analíticos y estudios más amplios para examinar los efectos del cambio climático sobre los primeros habitantes de los Andes Centro-Sur. No obstante, para crear el modelo de trabajo ideal para abordar el estudio del periodo Arcaico se requieren aún más estudios paleoclimáticos locales y un mayor esfuerzo para integrar la información a los estudios arqueológicos sistemáticos. Por ejemplo, las investigaciones de Aldenderfer y sus colegas han intentado crear una reconstrucción detallada de los valles de Ilave y Ramis (Farabaugh y Rigsby 2005; Rigsby et al. 2003; Rigsby et al. 2002), combinando estos estudios con prospecciones regionales completas y excavaciones extensivas en varios sitios (Aldenderfer 2009:80).

\section{Tareas por Hacer}

Obviamente, hemos aprendido mucho sobre el periodo Arcaico en las últimas décadas, pero todavía hay grandes vacíos en la amplia geografía regional, así como conceptual, dignos de debate (Aldenderfer 2009:81). Por lo general, el Arcaico puede ser dividido en cuatro períodos: Arcaico Temprano (10.000-8.000 a.p.), Arcaico Medio (8.000-6.000 a.p.), Arcaico Tardío (6.000-4.000 a.p.) y Arcaico Final (4.000-3.400 a.p.) (Aldenderfer 2011). Previo al Arcaico se considera un periodo Paleoindio, sin embargo como discutiremos, hay diferentes posiciones sobre la existencia o no de una clara demarcación entre estos períodos. 
Los orígenes. ¿Por dónde llegaron, en qué condiciones climáticas, qué cultura trajeron los primeros hombres a los Andes Centro-Sur y cómo se dio el paso hacia el período Arcaico?

El sitio Monte Verde en el sur de Chile, con una antigüedad algo mayor de 14.000 años a.p. (Dillehay 2004), es una evidencia tan temprana del hombre en el sur de Sudamérica, que nos obliga a preguntarnos ¿por dónde llegaron estos hombres extraordinariamente antiguos? Varios colegas han hecho una revisión importante sobre el problema del Paleoindio en los Andes Centro-Sur, dando una impresión que la primera ocupación fue más antigua que la de Clovis y al parecer por medio de varias rutas (Jackson et al. 2003; Núñez y Santoro 1990; Santoro y Latorre 2009).

Uno de los problemas que se discute sobre el Paleoindio sudamericano, al menos del sur del continente, es la difusa asociación entre la fauna extinta y el estilo de los artefactos, como sí sucede en Norteamérica (Lynch 1988). Por el contrario, el Paleoindio en los Andes Centro-Sur muestra un aprovechamiento de los diversos ecosistemas locales, como el marítimo (DeFrance y Umire 2004; Sandweiss et al. 1998), así como una gran diversidad de sus herramientas (Bruhns 1994:4363). Pero como bien han señalado Santoro y Latorre (2009:17) este problema es más profundo, llamándonos a la búsqueda de respuestas para los problemas como los que se han planteado en el título de esta sección.

Los sitios más antiguos que se conocen en los Andes Centro-Sur del Perú son costeros: Quebrada Jaguay y Quebrada Tacahuay. Ambos demuestran ocupaciones fechadas en el Pleistoceno Tardío (13.000 a 11.000 a.p.) y en una segunda fase del Holoceno Temprano que se prolonga hasta los 8.000 a.p. (DeFrance y Umire 2004; Keefer et al. 1998; Sandweiss et al. 1998). Estos datos, así como la gran especialización marítima que muestran sitios costeros del Holoceno Temprano, han permitido sugerir una posible ruta costera para el poblamiento andino (Lavallée et al. 1999b: 414; Llagostera 1977, 1979; Sandweiss et al. 1998: 1832), en contraposición a la idea de otros investigadores que proponen que los cazadores serranos se adaptaron a la costa forzosamente (Bonavia 1991; Núñez 1983).

Sin embargo, este agrupamiento de sitios pleistocénicos costeros en el sur del Perú contrasta con su ausencia en la costa del norte de Chile. Según
Santoro y Latorre (2009:26), esto se explica por problemas en las muestras de sitos excavados o investigados en dicha región.

Reportes recientes de una presencia paleoindia en el sitio Quebrada Maní 12, Atacama Norte, dan evidencia de una ocupación ca. 11.900-12.600 a.p. (Santoro et al., en este número). En Perú, aún faltan trabajos en la sierra occidental que puedan descubrir evidencias del Paleoindio. Sin embargo, la evidencia de obsidiana en Quebrada Jaguay, procedente de Alca, en el valle de Cotahuasi, sugiere que existieron pobladores que ingresaron a la serranía (Jennings 2002:17; Sandweiss et al. 1998:1832), tanto como la evidencia de una punta cola de pescado, elaborada en calcedonia, ubicada en la superficie del sitio Tillane, en la quebrada de Candabaya, alturas de Arequipa (Szykulski 2010).

Una ruta oriental es una segunda posibilidad, que parece casi desaforada sin haber por lo menos empezado la búsqueda de información sistemática. No obstante, no deja de ser una posibilidad, tomando en cuenta que durante el Pleistoceno Tardío parte de esta región pudo haber proporcionado pastizales, matorrales o sabanas (Clapperton 1993; León 2007:56-57, en base a los trabajos de Ray y Adams 2001), por lo cual, el acceso podría haber sido posible (Anderson y Gillam 2000). Por ejemplo, esta ruta ha sido planteada para la ocupación de las tierras argentinas (Núñez y Santoro 1990:127) en donde se documentan sitios, aunque sean dispersos (Borrero 1996; Politis 1991; Politis et al. 2004; Rivero y Berberián 2008). De esa forma también hubieran podido ingresar hacia el altiplano -no debería descartarse esa posibilidad, más aun si tomamos en cuenta que en la Amazonia se reportan evidencias del Paleoindio (Roosevelt et al. 1996).

Por lo tanto, el Paleoindio en los Andes CentroSur es aún problemático - a la vez en toda Sudamérica lo sigue siendo: "A través de toda Sudamérica nos faltan industrias líticas completas y consistentes, basadas en sitios de habitación, caza, y taller, tales como las que fueron utilizadas para definir las culturas norteamericanas Clovis y Folsom" (Lynch 1988:7). Hay una escasez de sitios del Pleistoceno Tardío en todas las regiones (Grosjean et al. 2005; Jackson et al. 2004; León 2009; Lynch 1986; Núñez et al. 2002), salvo pocos ejemplos, como el señalado en este número (Santoro y colegas). Hay que seguir buscando y excavando, incluso más allá de lo que llamamos estéril. 
Tan problemático como ubicar sitios Paleoindio, es discernir la transición del Pleistoceno Tardío al Holoceno Temprano (Núñez y Santoro 1990), debido a la falta de sitios estratificados que permitan caracterizarlos, tanto como la dificultad de identificarlos (Lynch 1988:7). No obstante, el cambio se dio y dejó huellas en su tecnología lítica y en las estrategias económicas que más adelante se configuró como el periodo Arcaico (León 2009).

En cuanto a la ruta amazónica, ésta no sólo es una posibilidad de estudio para rastrear a los primeros hombres de los Andes Centro-Sur, sino, como veremos a continuación, también para explicar el origen del desarrollo de la civilización.

\section{¿Qué sucedió en los flancos orientales de los Andes?}

Ha mejorado la investigación de los flancos orientales de los Andes Centro-Sur durante los últimos diez años; sin embargo, principalmente se ha centrado en los desarrollos culturales de los periodos tardíos, en temas como las relaciones interregionales, las prácticas funerarias, las consecuencias de la llegada de los Incas a las poblaciones orientales de frontera, así como en la caracterización de las poblaciones orientales locales -muchas veces tratando de conciliar la información arqueológica con la etnohistórica (Beierlein de Gutiérrez 2009; Coben y Stanish 2005; Flores et al. 2006; Michel et al. 2007; Oliveto y Ventura 2009; Román y Román 2011; Ventura 2010). En todo caso, aún es escasa la información sobre ocupaciones previas a nuestra era, por ejemplo, se ha investigado poco sobre el periodo Arcaico (Aldenderfer 2009:81).

Lo interesante de esta situación es que existen fuertes posiciones que mantienen la importancia del flanco oriental y la influencia de la Cuenca Amazónica en el surgimiento de la civilización andina (Lathrap 1971, 1985; Morales 1993; Tello 1942). Lo que es sorprendente es que aún no se ha elaborado una investigación concienzuda de largo plazo para comprobar o refutar esta hipótesis.

En consecuencia, no tenemos idea de cómo se desarrollaron los antiguos contactos entre la Cuenca del Amazonas y las tierras altas de los Andes durante el Arcaico, cómo pudo haber sido y la forma que tomó. Un mejor conocimiento del Arcaico ayudaría reconstruir el proceso y explicar la "sorprendente" aparición de estas características de la civilización (Aldenderfer 2009:81). Como pura especulación, nos imaginamos que los primeros contactos (si no consideramos a los migrantes originales) tomaron la forma de intercambios de bienes a larga distancia, trayendo plumas, piedras preciosas ${ }^{1}$, plantas y sustancias alucinógenas ${ }^{2}$, alimentos exóticos, medicinas $^{3}$, y otros bienes de prestigio o estatus.

En otras partes de los Andes Centro-Sur algunos arqueólogos y antropólogos físicos chilenos sugieren un origen transaltiplánico de las poblaciones costeras del periodo Arcaico, específicamente para la cultura Chinchorro (Rivera 1975; Rivera y Rothhammer 1986; Rothhammer et al. 1986; Rothhammer y Silva 1992). Esta hipótesis se basa en medidas craneofaciales y paralelos generales de prácticas rituales de las culturas costeras y amazónicas, así como la presencia de ecofactos en sitios costeros. Bien puede ser que hubo algún tipo de contacto entre los flancos orientales y la costa pacífica de Chile, pero son escasas las evidencias actuales que apoyan la teoría. La idea requiere manifestación del contacto, no sólo basado en la presencia de rasgos u objetos amazónicos en sitios costeros, sino también de datos arqueológicos provenientes de sitios ubicados y excavados en el altiplano, la sierra oriental, y propiamente, la Amazonia, que muestre el proceso de movimiento o desplazamiento poblacional entre dichas regiones. Incluso tal afirmación podría ser reforzada por los estudios de ADN antiguo.

Una buena comprensión de esto se viene elaborando en el noroeste de Argentina, donde se ha documentado de manera concreta el contacto entre los habitantes de la puna salada y las tierras bajas (Mendoza 2002).

Al otro lado de los Andes Centro-Sur se están realizando estudios de $\mathrm{ADN}$ sobre los restos humanos del norte de Chile (Moraga et al. 2001; Moraga et al. 2000), mostrándose una proximidad genética de las momias y los grupos Aymaras y Atacameños con los aborígenes amazónicos. Aunque en las investigaciones recientes se ven evidencias de posibles flujos migracionales desde la vertiente oriental de los Andes y/o de las tierras bajas tropicales, al menos desde el periodo Arcaico Tardío/Formativo Temprano (Rothhammer et al. 2009), todavía no se ha demostrado de manera concreta un origen arcaico transaltiplánico de estos pueblos costeros.

\section{¿Dónde está el Arcaico boliviano?}

No es tanto que el Arcaico en Bolivia no se conozca, más bien, es muy poco conocido porque 
ha sido poco investigado, existiendo aspectos desconcertantes de nuestra falta de conocimiento, y a la vez, aspectos expectantes (Aldenderfer 2009:81). Como lo han señalado los propios arqueólogos bolivianos (Arellano 1992:309; Michel 2008; Rivera 2004; Rivera y Strecker 2005:12) las investigaciones sobre el periodo Arcaico son las más desconocidas de Sudamérica y principalmente están basadas en estudios no sistemáticos de sitios superficiales y sus materiales. Por ejemplo, Arellano y Kuljis (1986) describen restos precerámicos superficiales en la cuenca del Río Maure, al suroeste de Desaguadero. También en la región de Lípez-Potosí se reportan sitios con materiales líticos que lo asocian tanto al Arcaico como al Paleoindio (Arellano 1987; Berberián y Arellano 1978), ubicados frecuentemente en las orillas y ríos que desembocan en los lagos (Arellano 2000). Datos similares -también superficiales y preliminares- de restos líticos asociados a riberas de lagos y ríos se mencionan para la zona de Tarija, entre el sur de Bolivia y el noroeste de Argentina (Michel et al. 2007:85).

El sitio icónico de la arqueología temprana andina es Viscachani, que se encuentra en el altiplano oeste boliviano (Ibarra Grasso 1957; Patterson y Heizer 1965). Este sitio por años ha servido como base para las comparaciones con otros asentamientos arcaicos y sus colecciones de artefactos, con localidades tan lejanas como el norte del Perú y los Andes centrales. Las tipologías construidas para la colección de bifaciales y puntas de proyectil de Viscachani han dado una visión de las posibles conexiones de larga distancia a través de los Andes; la tecnología de herramientas de piedra reducida asimismo ha servido como punto de partida para los esquemas evolutivos del cambio cultural. Todo esto se logró a pesar de un gran problema con el sitio: nunca se había excavado, ninguno de sus componentes había sido radiométricamente fechado y, por lo tanto, la cronología del sitio "flota" en el tiempo, convirtiéndose en una tipología relativa, mientras que otras tipologías más exactas fueron creadas para el Arcaico. Viscachani sigue siendo importante, pero ya no tiene el brillo que tuvo hace cuarenta años (Aldenderfer 2009:81).

Otras áreas de Bolivia vienen siendo mejor integradas a las secuencias regionales conocidas. Barfield (1961) describió varios sitios en el extremo oeste de Bolivia cerca de la frontera con Chile y Argentina alrededor de los salares Laguna Colorada y Laguna Hedionda. Sobre el lado chileno, Gustavo
LePaige (1958) llegó a estudiar la adyacente región de Atacama por décadas y creó una secuencia cultural cronológica relativa basada en excavaciones estratigráficas y comparaciones tipológicas. Fechados radiocarbónicos y reconstrucciones paleoambientales extensivas han dado validez a una gran parte de la cronología relativa, dando lugar a una perspectiva importante del proceso cultural y la adaptación económica que resultó del cambio y la variabilidad climática (Núñez et al. 2002).

Otra área de Bolivia que sigue siendo desconcertante es la cuenca del Lago Titicaca. Las evidencias más tempranas del lado boliviano del lago provienen de la Isla del Sol, donde Stanish y sus colegas (2002) descubrieron una ocupación del periodo Arcaico fechado en 3.780 años a.p. (2.7001.600 cal. a.C.). Ellos mantienen que al sitio pudo accederse por embarcaciones, pero recientes estudios batimétricos muestran que el sitio pudo haber estado conectado con el continente (D'Agostino et al. 2002). Sin embargo, este debate no es de tanta importancia; en cambio, la observación de que el sitio se encontraba cerca de la margen del lago sugiere que el lago mismo se consideró un recurso valioso para el periodo Arcaico Tardío o Terminal. También es evidente que muy poco del período Arcaico se ha perdido por la subida del nivel del lago principal que ocurrió en algún momento alrededor de 3.500 a.p. (Craig et al. 2009).

Aún no se ha documentado mucha ocupación perteneciente al Arcaico en los estudios arqueológicos del lado boliviano del lago. Bandy (2001:87) no reportó sitios del Arcaico, en su estudio de la Península de Taraco, que se extiende en el Lago Winyamarca, contiene evidencia del Arcaico. Señala, sin embargo, que dicho lago permaneció seco durante una gran parte del periodo, y lo que serían sus márgenes se utilizó de manera intensiva solamente después de que el lago fue rellenado luego de 3.500 a.p. Al este, en el interior del Valle de Tiwanaku, Albarracin-Jordan y Mathews (1990:51-53) descubrieron sólo dos sitios del periodo Arcaico durante su prospección. No obstante, en el lado peruano del lago, en los valles de los Ríos Ilave, Huenque y recientemente en la cuenca del Río Ramis, se han documentado cientos de sitios arcaicos (Aldenderfer y Flores Blanco 2008; Aldenderfer y Klink 1996; Klink 2005).

Estas diferencias son impactantes y requieren alguna explicación. Se podría razonar que, al menos en las prospecciones anteriores, no se previeron sitios 
arcaicos y, por tanto, se pasaron por alto o fueron ignorados. Otra explicación es que los procesos naturales o culturales postdeposición pueden haber contribuido a la destrucción de los registros del Período Arcaico o, quizá, modificado de tal manera que no fue reconocido. Esto parece inverosímil, teniendo en cuenta que trastornos similares han sucedido en el lado peruano del lago. También puede ser que la mayor parte del lado boliviano del lago simplemente no fue utilizada durante el Arcaico, y solamente fue después de que empezó a llenarse que los habitantes prehistóricos tuvieron motivo para aprovechar ese ambiente. Esto parece estar en contradicción con la existencia de Viscachani y la ocupación extensiva del Arcaico al lado peruano. También hay que preguntarse "de dónde llegaron los habitantes del Formativo Temprano del lago".

En resumen, hay muchas más preguntas sobre el Arcaico boliviano que aún no las podemos contestar; hasta que se resuelvan, estamos en posición de desventaja para abordar el estudio de sus procesos culturales (Aldenderfer 2009:82).

En este contexto, el aporte reciente de los colegas bolivianos resulta fundamental. Con su prospección sistemática de la región de Oruro, sierra central boliviana, colindante al Lago Uru-Uru, Capriles y colegas (en este número) reportan por lo menos treinta y cinco sitios arcaicos emplazados a las orillas del lago. Anteriormente, McAndrews (2005:2) había reportado la inexistencia de sitios del Arcaico en el mismo departamento.

Más al sur, Marcos Michel (2008) reportó la existencia de dos sitios: SH 19 y SH 25, ubicados en la región de Santiago de Huari, al sureste del Lago Poopó, en el centro de áreas de humedales y a las orillas de ambos brazos del río que baja de la quebrada de Jikiri Kollu. Por su tipología los relaciona al Arcaico Tardío. Los sitios consisten de una dispersión superficial de desechos líticos y puntas romboidales y foliáceas con retoque denticulado (Michel 2008:101).

Claudia Rivera y Sergio Calla (en este número; Rivera 2004) documentan otra área con ocupación arcaica, fuera de la serranía central, en los valles de Cinti y San Lucas, región de Chuquisaca, sur de Bolivia.

Se reportan doce sitios arcaicos en la parte alta del valle de Cinti, consistiendo en cuevas, abrigos rocosos, sitios al aire libre con pequeñas estructuras circulares, y áreas de caza con dispersiones de artefactos líticos (puntas de proyectil triangulares alargadas, ojivales, triangulares con pedúnculo, y una serie de otras piedras talladas). En la parte baja del valle se registraron cuatro sitios arcaicos más (Rivera 2004).

En el valle de San Lucas se han reportado treinta y tres asentamientos, tanto del Arcaico Medio como del Arcaico Tardío, casi todos apostados sobre terrazas aluviales cuaternarias inmediatas a los ríos y cursos de agua, así como sobre algunas colinas (Rivera y Calla, en este número).

El descubrimiento de estos sitios del Arcaico en Bolivia despierta nuestro interés y esperemos que pronto pueda cristalizarse en excavaciones intensivas en alguno de estos asentamientos. Además, como bien lo ha señalado Michel (2008:154), en Bolivia es necesario correlacionar las reconstrucciones paleoecológicas -como los niveles de alturas de los lagos- con la información arqueológica de patrón de asentamiento para poder entender el proceso de poblamiento.

\section{¿Cuánto sabemos del lado peruano del lago? El Arcaico en Puno}

Era prácticamente desconocido el Período Arcaico en el altiplano peruano hasta hace dos décadas; solamente se conocía por algunas breves descripciones de la cultura material (Menghin y Schroeder 1957; Palacios 1984; Palao 1989; Piu Salazar 1977).

Desde hace poco más de quince años se inició un reconocimiento sistemático para estudiar el Arcaico en la cuenca del Titicaca. Se empezó por los valles Ilave y Huenque, dándose a conocer al menos doscientos componentes arcaicos (Aldenderfer y Klink 1996; Klink y Aldenderfer 1996).

Otros proyectos de reconocimiento se iniciaron, todos cerca de la ribera del Titicaca, pero ninguno identificó sitios arcaicos (Erickson 1988; Frye y de la Vega 2005; Stanish et al. 1997).

Últimamente, nuevos proyectos han empezado a descubrir sitios arcaicos, en particular en la cuenca del Río Ramis y sus afluentes, los Ríos Huancané, Azángaro y Pucara en el norte del Titicaca (Aldenderfer y Flores 2008; Arizaca y Quispe 2005; Stanish y Plourde 2000; Stanish y Umire 2002).

Hasta la fecha ninguna excavación se ha hecho de sitios del Período Arcaico Temprano en la cuenca del Titicaca; no obstante, algunas puntas de proyectil recuperadas en el reconocimiento de Klink (2005) demuestran obvias semejanzas a las puntas de la Fase 
Khituña (9.500-8.700 a.p.) de Asana, sugiriendo que la ocupación más temprana de la cuenca cae dentro de este período temprano. Lo mismo se viene reportando en otras prospecciones (Aldenderfer y Flores 2008; Arizaca y Quispe 2005; Cipolla 2005).

Durante el siguiente período, en el Arcaico Medio, se observa un aumento dramático en la frecuencia de sitios en todas las cuencas, atribuible posiblemente a dos factores: un aumento de la población misma o una migración de gente de otras regiones. Los datos demuestran que la ubicación de sitios mayormente cae próxima a los tributarios de los ríos principales. Bases residenciales se ubicaron sobre las terrazas altas que daban vista a los valles (Rigsby et al. 2003); campamentos provisionales se ubicaron dentro de cuevas y abrigos pequeños; y estaciones para la caza se localizaron en situaciones donde había buena vista panorámica (Tripcevich 2002). Esta focalización sobre los ríos no es sorprendente ya que el período de 6.000-4.000 a.p. es un tiempo de mucha aridez (Craig et al. 2009).

La ausencia de sitios del Arcaico Medio en la margen del lago sugiere que la zona fue de poca importancia para aquella economía. La posibilidad de que algunos sitios del Arcaico Medio puedan estar bajo el nivel del agua del lago moderno es improbable (Aldenderfer 2011). Por ejemplo, el sitio Arcaico Medio más próximo a la orilla moderna del lago, en la cuenca de Huancané-Putina, queda a $12 \mathrm{~km}$ (Cipolla 2005:59); en Ilave, queda a $15 \mathrm{~km}$ (Aldenderfer 2011). Aunque la población del Arcaico Medio ciertamente aumentó, todos los índices de crecimiento sugieren que fue un proceso relativamente lento (Craig 2005).

Qillqatani nos ofrece una buena perspectiva de cómo puede haber sido el modo de vida durante el Arcaico Medio. Las excavaciones de este sitio demuestran que su ocupación más antigua (fechada en 7.250 a.p.) consistió en pequeñas estructuras junto a las paredes del abrigo, que ciertamente no pueden haber albergado más que unas cuantas personas. Los artefactos son mayormente de desechos líticos, algunas puntas de proyectil, y no se observan piedras de moler. Se descubren huesos de camélidos adultos y de cérvidos entre los restos de fauna, demostrando una preferencia por la caza de mamíferos grandes. También se identificaron muestras de Chenopodium silvestre que suplementaron la dieta. Por el tamaño $\tan$ pequeño de las estructuras y el inventario tan limitado de artefactos se infiere que pequeños grupos de cazadores utilizaron el sitio. De cualquier manera, este patrón de uso era común durante el Período Arcaico Medio (Aldenderfer 2011).

Cambios mayores ocurren en el asentamiento, la economía y el sistema social entre 6.000-3.400 a.p. en la cuenca del Titicaca. El patrón de asentamiento y la economía inferida del Arcaico Tardío es parecido al Arcaico Medio; sin embargo, el número de sitios con componentes Arcaico Tardío aumenta, así como la frecuencia de puntas de proyectil que se encuentran en el recorrido de los tributarios de la región. Esto sugiere que la población sigue aumentando durante este tiempo (Aldenderfer 2002, 2009, 2011).

Otro cambio que se observa en el Arcaico Tardío, particularmente después de 5.000 a.p., es un movimiento general hacia los márgenes del lago. A pesar de que el lago mismo permanece salado, es probable que empiece a estabilizarse y ser más atractivo cuando el clima mejora después de 4.500 a.p. Esto se observa en los reconocimientos del Huenque-Ilave y Huancané-Putina (Aldenderfer y Klink 1996; Cipolla 2005; Craig 2005; Klink 2005).

También se sondearon algunos sitios -Pirco y Kallachuro- y se excavó intensivamente en Jiskairumoko (Aldenderfer 2002, 2011; Craig y Aldenderfer 2002; Craig 2005; Craig 2011), los cuales ahora nos proporcionan una perspectiva más amplia del estilo de vida del Arcaico Tardío y Terminal (Aldenderfer 2011).

Pirco se ha interpretado como una base residencial de corto plazo (Craig 2005, 2011). En cambio, Jiskairumoko -con estructuras semisubterráneas fechadas ca. 4.500 a.p.- parece ser una base residencial dentro de un asentamiento semisedentario (Craig 2005, 2011). Aunque aún no se ha completado el análisis paleoetnobotánico, observaciones preliminares han identificado la presencia de tubérculos y Chenopodium silvestres, que seguramente fueron parte de la dieta. Ninguna evidencia de la domesticación del camélido se recuperó de este contexto (Aldenderfer 2011). En la cercanía, Kaillachuro es un sitio mortuorio, que consiste de nueve montículos bajos utilizados durante el Arcaico Tardío; la excavación de uno demostró la presencia de varios entierros secundarios, así como de un infante enterrado dentro de una caja de piedra (éste se fechó en 3.960 a.p.) (Aldenderfer 2011).

En el Arcaico Terminal ocurren cambios aún más dramáticos. Desde una perspectiva regional, aunque el número de sitios disminuye en el Arcaico 
Terminal, el tamaño de los sitios aumenta, sugiriendo un patrón de agregación de población. Estos sitios más grandes se sitúan sobre o cerca a terrazas aluviales de formación nueva, que coincide con una fase de mejoramiento climático que empieza a partir de 4.000 a.p. (Rigsby et al. 2003). La nueva formación de terrazas habría promovido la extensión de los recursos naturales de Chenopodium y tubérculos silvestres que, a su vez, habrían atraído a los recolectores del área (Aldenderfer 2011).

Los contextos del Arcaico Terminal en Jiskairumoko demuestran una aldea de cuatro estructuras subterráneas pequeñas y similares. Cada una tuvo alguna forma de almacenamiento y un fogón central. La presencia de grandes cantidades de moledores sugiere que la dieta consistió de plantas, y los análisis preliminares de restos paleoetnobotánicos indican que muestras de Chenopodium representan una combinación de plantas silvestres y cultivadas (Aldenderfer 2011; Rumold 2010). Craig (2005) sugiere que también existió cría de animales que se hubieran prestado para el intenso intercambio de bienes, como la obsidiana llegada desde Chivay (Craig y Aldenderfer 2005), e incluso de materias exóticas como el oro (Aldenderfer et al. 2008). Por lo visto, la ocupación del Arcaico Terminal_representa una vida semisedentaria (Aldenderfer 2011).

Jiskairumoko nos proporciona evidencia clara de la extensiva incorporación de plantas en la dieta prehistórica del Arcaico Terminal. En cambio, los datos de Qillqatani nos demuestran que, por lo menos, algunas gentes en la cuenca conocían el pastoreo a una altura de $4.420 \mathrm{msm}$. Dos estructuras circulares grandes, fechadas en 3.660 a.p., se encuentran adentro del abrigo, y los restos óseos indican que, aunque la caza del venado continuaba, los camélidos se acorralaban. También hay evidencia que Chenopodium cultivado estaría incorporado a la dieta, seguramente obtenido por intercambio con gentes de las sierras más bajas. La importancia del intercambio se confirma también por la presencia de instrumentos de obsidiana de Chivay. También se encuentran algunos tiestos cerámicos -quizá los más tempranos que se conocen en la cuenca del Titicaca, pero de origen aún incierto (Aldenderfer 2011).

Todos estos cambios que se observan en el Arcaico Terminal -y se desarrollan más ampliamente en el Período Formativo- forman la fundación de la sociedad compleja (Aldenderfer 2002, 2004, 2011; Craig 2005, 2011).
Aunque nuestros conocimientos del Período Arcaico en la región sur de Puno han avanzado en los últimos quince años, aún quedan muchos problemas que investigar: ¿Cómo fue el patrón de asentamiento en otras áreas de la cuenca del Titicaca? ¿Cuál es la función de las sierras orientales andinas durante el Arcaico? ¿Cómo fue el proceso de la transición al agropastoreo? ¿Cuál fue la importancia de los recursos del lago Titicaca en el proceso histórico durante el Holoceno? (Aldenderfer 2011).

\section{¿Cómo nos hemos venido ordenando temporalmente, cuánto se ha hecho y cuánto falta por hacer?}

La más temprana cronología en los Andes Centro-Sur viene de los contextos costeros. Max Uhle y Ricardo Latcham iniciaron su investigación cerca de Arica en 1908 (Willey 1998), y en la síntesis de su investigación, por la abundancia de materia lítica en la región, Uhle (1922) propuso un "Período Paleolítico". También describió los conjuntos acerámicos en términos culturales: los "Aborígenes de Arica" (que, en actualidad, es el complejo Chinchorro; Llagostera 1989). Esto encaja bien con el esquema del tiempo evolutivo prevaleciente en aquellos tiempos de investigación arqueológica.

Algunos años después, Junius Bird (1943) condujo una serie de excavaciones en Quiani, Pichalo, Playa Miller y Taltal, en que lo llevó a definir dos períodos cronológicos por su estratigrafía: Arica 1 y Arica 2.

Arica 1 fue una cultura acerámica basada en la pesca y la recolecta de marisco, y fue dividida en dos subfases, Quiani 1 y Quiani 2 (o período Precerámico I y II), la cual fue distinguida por "tipos fósiles" (anzuelos de conchas a diferencia de anzuelos de materiales compuestos ${ }^{4}$ ). Arica 2 fue más tardío, diferenciándose por ser cultura agrícola y con cerámica.

El inicio de la datación radiocarbónica en la década de 1950 revolucionó la reconstrucción de la cronología en la arqueología, y la técnica se incorporó rápidamente en las investigaciones andinas.

Si bien muchas de las secuencias que se habían generado por la excavación estratigráfica fueron verificadas, tomó algún tiempo antes de que fueran adoptados los nombres de las fases que se habían aceptado ampliamente, simplemente porque muy pocos sitios del Período Arcaico se habían 
excavado y aquellos se encontraban muy dispersos por toda la región. Por lo tanto, los arqueólogos se conformaron con un esquema de periodización del Arcaico (o Precerámico) Temprano, Medio, y Tardío y, utilizando datos radiocarbónicos, ubicaron los sitios (o los niveles de estos) en los períodos apropiados. El concepto del período llegó a ser una taquigrafía intelectual, no exclusivamente para el concepto del tiempo sino para algunos aspectos de los procesos culturales dentro del marco evolucionista en general.

En algunas áreas de los Andes Centro-Sur, específicamente en las tierras altas del extremo sur del Perú y del norte de Chile, los nombres de las fases y sus límites definidos son generalmente compatibles. En esta instancia, las fases están basadas en excavaciones intensivas y extensivas (en Asana) tanto como excavaciones restringidas en siete sitios al aire libre y abrigos rocosos en las cuencas del Osmore y el Río Chila en Perú (Aldenderfer 1998:69-75, 1999, $2000,2002)$ y en nueve abrigos rocosos en el norte de Chile (Santoro y Núñez 1987; Santoro 1989). En una serie de proyectos extensos en la cuenca del Río Ilave (Jiskairumoko, en particular), Aldenderfer y sus estudiantes definieron otro período, el Arcaico Terminal, que marca la transición de un modo de vida de forrajeo móvil a uno que fue más sedentario, con una economía basada en el pastoreo de camélidos y el uso intensivo del Chenopodium (Aldenderfer 2011; Aldenderfer y Barreto 2004; Craig 2005, 2011; Craig y Aldenderfer 2002). Aunque varios sitios se han excavado últimamente en la costa (Muñoz et al. 1993; Lavallée et al. 2000; Rasmussen 1998; Sandweiss et al. 1989; Schiappacasse y Niemeyer 1984; Wise 1999), aparte del famoso complejo Chinchorro y sus vestigios de humanos momificados (Arriaza 1995), se han desarrollado pocos nombres de fases, y el concepto del complejo cultural se usa como substituto.

Las puntas de proyectil tienen una larga historia de uso como marcadores cronológicos en los Andes Centro-Sur, pero sólo hace poco se desarrolló una tipología comprensiva. Por consecuencia, arqueólogos forzosamente tuvieron que comparar las puntas de los sitios superficiales o de las excavaciones con las mejores secuencias conocidas, como aquellos desarrollados por John Rick (1980) en Pachamachay en los Andes centrales, o de Santoro y Núñez (1987; Santoro 1989) para el norte de Chile. Esta táctica funcionó relativamente bien para los períodos tempranos, pero las comparaciones resultaron ser forzadas y, por lo general, insatisfactorias para los tiempos más tardíos debido a la regionalización de los estilos de punta, es decir, un número creciente de estilos dentro de un alcance geográfico limitado (Aldenderfer 1989). Sin embargo, debido al mayor volumen de trabajo, una mejor información, y el uso generalizado de datación radiocarbónica, Cindy Klink y Mark Aldenderfer (2005) desarrollaron una cronología de puntas de proyectil para las tierras altas de los Andes Centro-Sur. Este es un complemento bueno a la tipología de Rick, así como al de Núñez y Santoro, y es capaz de captar la variabilidad local en la región con mayor detalle. Aunque no aborda directamente el litoral, un repaso de la literatura demuestra que muchos de estos tipos aparecen en diversos contextos allí. A pesar de que todavía se ata a la cronología basada sobre el concepto del período, esperamos clarificarlo en el futuro para asociar los estilos tan estrechamente como sea posible con intervalos de tiempo específicos.

\section{Resumiendo lo que nos falta por hacer: estudiar los procesos}

¿Por dónde empezar? Aunque hemos tomado grandes pasos en avanzar nuestros conocimientos de la historia cultural en los Andes Centro-Sur, tenemos menos control sobre otros aspectos del proceso cultural. Obviamente, esta situación cambiará a medida en que el volumen del trabajo realizado del Período Arcaico aumente, pero esto tomará tiempo.

Desde nuestra perspectiva (Aldenderfer 2009) $-y$ en manera de resumen sobre temas que ya hemos abordado en este artículo- las preocupaciones generales son las siguientes:

(1). La mayoría de los arqueólogos que trabajan en la región confían en que la vía principal de la primera migración de los seres humanos en la región sea a lo largo de la costa del Pacífico y de allí a la sierra a través de los valles del flanco occidental. Las investigaciones de sitios de la sierra (p.ej., Aldenderfer 1998, 1999; Núñez et al. 2002) y costa (p.ej., Keefer et al. 1998; Muñoz et al. 1993; Lavallée et al. 1999a, 1999b; Sandweiss et al. 1998) han confirmado la validez general de esta afirmación. Sin embargo, algunas preguntas acerca de este proceso aún permanecen. Los primeros estilos de puntas de proyectil documentados en el sur del Perú y el altiplano del extremo norte de Chile son formas pedunculadas; el estilo que sigue tiene hombros con espinas (Klink y Aldenderfer 
2005). Estas formas se fechan generalmente ca. 10.000 a.p. En Asana, por ejemplo, las puntas más tempranas se encuentran en la fase Khituña (10.100 y 8.300 a.p.) (Aldenderfer 1998:131, 1999:382). Sin embargo, en la puna salada de Chile, incluso la región de Atacama, el estilo más temprano es la punta Tuina, una punta pequeña, ovoide, y a pesar de que es contemporánea o anterior a los materiales de Asana, es en forma totalmente diferente (De Souza 2004; Núñez 1992:288; Núñez et al. 2002). Similar forma de punta triangular también es reportada en el Noroeste argentino (Hocsman 2010). Tomando en cuenta la gran cantidad de investigaciones realizadas en la región por Núñez y sus colegas, las diferencias parecen ser válidas, y por lo tanto se plantean una serie de preguntas sin respuestas: ¿Puede ser que la diferencia de estilo se debe a la función, origen étnico, una migración anterior, o quizá una migración de alguna otra dirección? (Aldenderfer 2009:82). Por tanto ¿existe una o varias migraciones y rutas en este proceso?

(2). Nos hace falta una mejor comprensión de la variabilidad y las trayectorias del desarrollo de la producción de alimentos de bajo nivel (sensu Smith 2001). Los Andes Centro-Sur gozan de una diversidad de conjuntos de producción de alimentos -el pastoreo y la economía agropastoril del altiplano, el cultivo de los valles de los flancos occidentales y la pesquería del litoral Pacífico y de las costas del Lago Titicaca. No obstante, sugerimos que sería ventajoso dirigir nuestra atención a las circunstancias locales específicas, tanto para el tema del pastoreo como para entender el surgimiento de las economías hortícolas de los valles medios del flanco oeste y oriental de los Andes Centro-Sur.

Por lo general, ha prevalecido la versión que el pastoreo fue fundamental en este proceso de domesticación, focalizando el interés por estudiar dicho tema (Cartajena et al. 2007; Núñez et al. 2006; Olivera y Tchilinguirian 2006), incluso proponiendo que el pastoreo fue un proceso paralelo e independiente al de los Andes centrales (Cartajena et al. 2007; Yacobaccio 2003).

Los restos óseos que se conocen de la región fueron recuperados tanto de abrigos como de sitios al aire libre que reflejaron una amplia secuencia de ocupación que comienza con el consumo predatorio de camélidos durante el Arcaico Temprano, llegando hasta un nivel de 50\% en preferencia de consumo de carnes (Yacobaccio 2003). En el Arcaico Medio se produce una gran modificación hacia una intensificación en la caza, aumentándose al 83\% la predilección de consumo (Yacobaccio 2003).

Durante el Arcaico Tardío conviven grupos de auquénidos -vicuñas y una especie cuyo tamaño cae dentro de un rango equivalente al guanaco norandino y el de la llama. En el noroeste argentino, por los 4.100 a.p., hay evidencias de confinamiento de camélidos en Inca Cueva 7 (Yacobaccio 2003; Aschero y Hoscman, en este número). En Asana se reporta un nivel fechado en 3.800 a.p. en el cual el $\mathrm{pH}$ del sedimento tiene niveles de potasio, y de textura muy parecida a la de los corrales modernos, por lo cual se ha propuesto que fue depósito de guano (Aldenderfer 1998). Según la información alométrica y osteométrica disponible (Yacobaccio 2003), hacia 3500-3400 a.p. se observa en el registro arqueológico un animal del tamaño y peso de la llama carguera actual. En la quebrada Tulán, Puna de Atacama, también se ha reportado este proceso de domesticación (Cartajena et al. 2007); y como se ha señalado anteriormente, en Qillqatani ya existía acorralamiento de animales por los 3.660 a.p. (Aldenderfer 2011).

Al final, estos acontecimientos evolucionaron hacia la economía basada en un complejo manejo de los camélidos durante el Formativo Temprano, alrededor de 3.100 a.p. (Cartajena et al. 2007; Núñez et al. 2006).

Con respecto al proceso del cultígeno, nuestro conocimiento de ciertas especies es prácticamente nulo; por ejemplo, ¿cómo fueron introducidos al interior el maíz y otros cultígenos en las economías agrícolas de estas poblaciones? Recordemos que en las economías marítimas aparece en algún momento el algodón, que, además de su uso obvio en la economía local, se puede haber utilizado para fabricar textiles, como bien de lujo o de prestigio en el comercio con las tierras altas (Aldenderfer 1999). Sin embargo, hasta la fecha, sólo tenemos indicios de cómo algunas de estas productoras de alimentos surgieron y se transformaron a través del tiempo.

Puede ser que sea de mayor importancia la documentación de estas trayectorias productoras en regiones como la cuenca del Lago Titicaca; después de todo, fue en esta área donde las sociedades complejas emergieron por primera vez en los Andes Centro-Sur y en donde supuestamente se dieron los primeros cultígenos, como sucedió con el Chenopodium y la papa (Bruno 2005; Spooner et al. 2005). Con el medio ambiente mejorado y con la formación de terrazas aluviales -como la 
T2 en Ilave- por los 4.200 a.p., un nuevo hábitat se prestó para el crecimiento de tubérculos y granos (Aldenderfer 2009:80).

Sin embargo, nuestro conocimiento está extraordinariamente incompleto de cómo las economías de forrajeo de las tierras altas se convirtió en la compleja economía agrícola de la prehistoria tardía - una economía que logró desarrollar una tecnología agrícola de acuerdo con su medio, mediante qochas y camellones (Erickson 1988; Flores et al. 2011). El desarrollo de este conocimiento necesariamente implica una mayor atención a las plantas domesticadas. No obstante, debido a los problemas de la preservación de los restos de estas especies, develar esto será difícil. Consciente de que los tubérculos y Chenopodium constituyeron la base de los excedentes de las complejas sociedades de la cuenca, tenemos que averiguar exactamente cómo sucedió esto.

Empezando con los pocos datos al respecto, en el sitio de Wayñuna en la sierra occidental sur del Perú, a $3.625 \mathrm{msm}$, sobre el valle de Cotahuasi, al interior de una estructura de contexto Arcaico Tardío ca. 4.000 años a.p., se han identificado residuos de almidón de ají, maíz, arrurruz y papa en las herramientas del procesamiento de alimentos (Jennings 2002; Rademaker 2006). Estos datos indican que los residentes de Wayñuna cultivaban estas especies y las preparaban como alimentos en dicho lugar (Perry et al. 2006; Perry et al. 2007:987).

Por otro lado, en la costa son escasos los datos sobre la producción de alimentos; sin embargo, la presencia de un fitolito de calabaza domesticada en el sitio Quebrada de los Burros (nivel N2), datado en 6.839 cal a.p., despierta muchas expectativas sobre el tema, como lo señalan Lavallée y colegas (en este número; Chevalier 2008:156).

En el noroeste argentino aún existen controversias por saber si las prácticas domesticadoras se dieron originalmente, se incluyeron en las prácticas a raíz de contactos entre poblaciones, o quizá, simplemente se obtuvieron los productos por intercambios comerciales (Aschero y Hocsman, en este número; Olivera 2001). A pesar de ello, la puna argentina debe ser una de las regiones serranas en que mejor se conoce la variedad de recursos vegetales consumidos, así como su producción a pequeña escala por los 3.600 a.p. Por lo mismo, nos recuerda, que si bien es muy importante la economía pastoril para estas sierras, también se debe tomar en cuenta la horticultura/agricultura (Aschero y Hocsman, en este número; Babot, en este número).
(3). Hoy sabemos que las sociedades complejas emergieron en varios lugares de los Andes CentroSur. No obstante, nos mantenemos en la ignorancia de precisamente cómo sucedió y, de hecho, de su trayectoria hacia la complejidad. Esta situación fuertemente contrasta con nuestro amplio conocimiento de otras zonas del mundo que produjeron estados arcaicos, como Mesopotamia (Matthews 2003) y el valle de Oaxaca (Marcus y Flannery 1996), entre otros.

A pesar de que tenemos volúmenes de síntesis sobre los orígenes de las sociedades complejas en el altiplano, la consideración formal de esta etapa solamente empieza por los 3.500 a.p. (Stanish 2003: Figura 5.1). De hecho, esta fecha es casi emblemática en los Andes Centro-Sur. En alguna forma la complejidad simplemente parece ocurrir a la vuelta de ese tiempo. Por ejemplo, Binford y colegas (1997:242), en la discusión de cambios a largo plazo en los niveles de agua del Lago Titicaca sostienen que "La insuficiencia del agua inhibe la agricultura intensiva y el desarrollo de grandes poblaciones sedentarias". Esta afirmación apoya la teoría que el sedentarismo sólo puede desarrollarse con la agricultura, y que ésta surgió de manera rápida e inmediata al desarrollo de mejores condiciones en el 3.500 a.p. Al contrario, como Aldenderfer (2004) ha demostrado, existe un preludio del desarrollo del poder en los Andes durante el Arcaico Tardío, a pesar de que dicha evidencia señala una forma de desigualdad y complejidad, que lamentablemente no es sustancial para demostrar un liderazgo persistente. Sin embargo, dichas semillas sí se observan en algunas partes de los Andes Centro-Sur - por ejemplo, en la cuenca del Río Ilave- donde para engrandecerse se obtuvo oro de los Andes orientales en torno al 4.000 a.p. Aunque esta forma de liderazgo no se mantuvo a largo plazo en la zona de Ilave, el hecho proporciona claves de lo que debe buscarse en aquellas zonas de la cuenca en la que los principios de la complejidad se desarrollaron aun más, por ejemplo, en los alrededores de Chiripa en la cuenca sur y Pukara en el norte. Últimamente, hemos realizado una prospección sistemática precisamente en el valle del Río Ramis, donde Pukara está ubicado (Aldenderfer y Flores 2008); los datos preliminares sugieren un patrón de agregación similar como el de Ilave, en que se ven una cantidad menor de sitios, pero éstos son de tamaños más grandes al final del Período Arcaico. Es sumamente interesante observar 
la existencia de complejos del Período Formativo superpuestos sobre los del Arcaico (Aldenderfer y Flores 2008).

También se reporta la recurrencia de sitios Arcaicos Tardío/Terminal/Formativo en otras regiones como las señaladas en este número (Capriles et al. en este número; Aschero y Hocsman, en este número). Este hecho, entre otros indicadores, se interpreta como una tendencia que llevó al incremento poblacional, el desarrollo de la vida sedentaria y la complejidad social en varios lugares de los Andes Centro-Sur (Aldenderfer 2004; Núñez 1983; Wise 1999).

\section{Conclusiones}

La buena noticia es que después de muchos años de abandono, el Período Arcaico ha llegado finalmente a sí misma como un tema digno de estudio extenso. Esto no es noticia nueva para arqueólogos chilenos o argentinos, que han tratado el tema por muchas décadas. Sin embargo, es alentador ver que los arqueólogos peruanos y bolivianos y sus colaboradores extranjeros han hecho enormes esfuerzos para definir el Arcaico en sus respectivos países. La prospección arqueológica sistemática se está convirtiendo en la norma, y esto resulta en la identificación frecuente de sitios arcaicos al aire libre.

La mala noticia es que aún tenemos mucho camino por recorrer con respecto a nuestra comprensión del Arcaico, tanto como que el registro arqueológico está amenazado cada vez más. Aunque los sitios de todos los períodos son destruidos por construcción, agricultura, y el "desarrollo", los del
Arcaico en particular corren peligro de extinción. En la cuenca del Titicaca, por ejemplo, el inicio de la labranza mecanizada ha destruido un gran número de sitios al aire libre en las terrazas que rodean los ríos principales. En cambio, los sitios con restos arquitectónicos presentan un obstáculo visible, y por lo mismo, tienden a no ser continuamente arados. Sin embargo, los llamados "basurales" o "cenizales" no ofrecen ninguna resistencia verdadera. En los valles del flanco occidental el crecimiento demográfico ha llevado a la expansión urbana a lo largo de las laderas y terrazas de los drenajes. Aunque muchas partes de los Andes Centro-Sur aún no han sentido el efecto de estas tendencias, aquellas son zonas que tienden ser las más aisladas y poco probables de rendir un registro amplio del Período Arcaico que pueda proporcionar los datos nuevos para resolver nuestros temas de investigación. Colegas, tenemos mucha investigación por hacer.

Agradecimientos: En primer lugar, queremos agradecer a los asistentes del Simposio "El periodo Arcaico en los Andes Surcentrales: Tradiciones Culturales e Innovaciones Tecnológicas", llevado a cabo en Ciudad de México en julio 2009, como parte del $53^{\circ}$ Congreso Internacional de Americanistas, de cuyas exposiciones y la lectura de sus primeros textos nos sirvieron de cantera de ideas para elaborar este artículo. De igual forma, quedamos agradecidos con los editores de Chungara Revista de Antropología Chilena y con los evaluadores anónimos, cuyos comentarios nos permitieron mejorar este documento.

\section{Referencias Citadas}

Abbott, M., M.B. Binford, M.W. Brenner y K.R. Kelts 1997. A 3500 14C yr High Resolution Record of Lake Level Changes in Lake Titicaca, South America. Quaternary Research 47:169180.

Abbott, M., B.B. Wolfe, A.P. Wolfe, G.O. Seltzer, R. Aravena, B.G. Mark, P.J. Polissar, D.T. Rodbell, H.D. Rowe y M. Vuille 2003. Holocene Paleohydrology and Glacial History of the Central Andes using Multiproxy Lake Sediment Studies. Palaeogeography, Palaeoclimatology, Palaeoecology 194:123-138.

Albarracin-Jordan, J. y J. Mathews 1990. Asentamientos Prehispánicos del Valle de Tiwanaku. Vol. 1. Producciones CIMA, La Paz.

Aldenderfer, M.S. 1989. The Archaic Period in the South-Central Andes. Journal of World Prehistory 3:117-158.

- - - 1998. Montane Foragers Asana and the South-Central Andean Archaic. University of Iowa Press, Iowa City.
- - - 1999. Cronología y conexiones: Evidencias precerámicas de Asana. Boletín de Arqueología PUCP 3:375-391.

- - - 2002. Late Preceramic cultural complexity in the Lake Titicaca basin. Ponencia presentada en el $67^{\text {th }}$ Annual Meeting of the Society for American, Denver.

- - - 2004. Preludes to power in the highland Late Preceramic Period. Archaeological Papers of the American Anthropological Association 14:13-35.

- - - 2009. Key research themes in the South-Central Andean Archaic. En Andean Civilization. A Tribute to Michael E. Moseley, editado por J. Marcus y P. Ryan, pp. 75-88. Monograph 63 Cotsen Institute of Archaeology, University of California, Los Angeles.

- - - 2011. Balances y perspectivas del periodo Arcaico en la región del altiplano. En Arqueología de la Cuenca del Titicaca, 
Perú, editado por L. Flores y H. Tantaleán. Cotsen Institute of Archaeology, University of California, Los Angeles. En prensa.

Aldenderfer, M.S. y M. Barreto 2004. Excavaciones arqueológicas a Jiskairumoko de la Cuenca del Río Ilave Sub-Región de Puno Región "José Carlos Mariátegui”. Reporte enviado al Instituto Nacional de Cultura.

Aldenderfer, M.S., N. Craig, R.J. Speakman y R.S. PopelkaFilcoff 2008. 4000-year Old Gold Artifacts from the Lake Titicaca Basin, Peru. Proceedings of the National Academy of Sciences of the United States of America 105(13):5002-5005.

Aldenderfer, M. y L. Flores 2008. Informe final del proyecto de investigación: "Prospección arqueológica, con excavaciones restringidas, en la Cuenca del Ramis (parte baja del río Pucara y el río Ramis), Puno-Perú". Presentado al Instituto Nacional de Cultura.

Aldenderfer, M.S. y C. Klink 1996. Archaic Period settlement in the Lake Titicaca Basin: Results of a recent survey. Ponencia presentada en el 36th Annual Meeting for the Institute for Andean Studies, Berkeley.

Anderson, D.G. y J.C. Gillam 2000. Paleoindian colonization of the Americas: Implications from an examination of physiography, demography, and artifact distribution. American Antiquity 65:43-66.

Arellano López, J. 1987. Primeras evidencias sobre el Paleoindio en Bolivia. Investigaciones Paleoindias al sur de la Línea Ecuatorial. Estudios Atacameños 8:186-197.

- - - 1992. El desarrollo cultural prehispánico en el altiplano y valle interandinos de Bolivia. En Prehistoria Sudamericana: Nuevas Perspectivas, editado por B. Meggers, pp. 309-325. Taraxacum, Washington, DC.

- - - 2000. Arqueología de Lipes, Altiplano Sur de Bolivia. Pontificia Universidad Católica del Ecuador, Quito.

Arellano López, J. y D. Kuljis 1986. Antecedentes preliminares de las investigaciones arqueológicas en la zona circumtitikaka de Bolivia (sector occidental sur). Prehistóricas 1:9-28. Universidad Mayor de San Andrés (La Paz).

Argollo J. y P. Mourguiart 1995. Paleohidrología de los últimos 25,000 años en los Andes bolivianos. Bulletin de l'Institut Français d'Études Andines 24:551-562.

- - - 2000. Late Quaternary climate history of the Bolivian Altiplano. Quaternary International 72:37-51.

Arizaca, E. y V. Quispe 2005. El Período Arcaico en la Cuenca del rio Ayaviri, Puno (Prospección arqueológica). Tesis para optar al título profesional de arqueólogo. Universidad Nacional de San Antonio Abad del Cusco, Cusco.

Arriaza, B.T. 1995. Beyond Death: The Chinchorro Mummies of Ancient Chile. Smithsonian Institution Press, Washington, DC.

Aschero, C. 1984. El sitio ICC-4: Un asentamiento precerámico en la quebrada de Inca Cueva (Jujuy, Argentina). Estudios Atacameños 7:53-64.

Bandy, M. 2001. Population and History in the Ancient Titicaca Basin. Unpublished Ph.D. Dissertation, Department of Anthropology, University of California at Berkeley.
Baker, P.A., S.C. Fritz, J. Garland y E.J. Ekdahl 2005. Holocene Hydrologic Variation at Lake Titicaca, Bolivia/Peru, and its Relationship to North Atlantic Climate Variation. Journal of Quaternary Science 20:655-662.

Baker, P., G. Seltzer, S. Fritz, R. Dunbar, M. Grove, P. Tapia, S. Cross, H. Rowe y J. Broda 2001. The history of South American precipitation for the past 25,000 Years. Science 291:640-643.

Baker, P.A., C. Rigsby, G.O. Seltzer, S.C. Fritz,T.K. Lowenstein, N.P. Bacher y C. Veliz 2001. Tropical climate changes at millennial and orbital timescales on the Bolivian Altiplano. Nature 409:698-701.

Barfield, L. 1961. Recent discoveries in the Atacama Desert and Bolivian Altiplano. American Antiquity 27:93-100.

Beierlein de Gutiérrez, M. 2009. La cerámica prehispánica tardía del altiplano de Sama y su relación con las regiones vecinas: Una aproximación arqueológica a la complejidad cultural de la microrregión Noroeste Argentino-Sur de Bolivia. Estudios Atacameños 37:51-61.

Berberián, E. y J. Arellano 1978. Los cazadores y recolectores tempranos en la región de Lípez (departamento de Potosí). Instituto Nacional de Arqueología, documentos 37/78.

Betancourt, J.L., C. Latorre, J. Rech, J. Quade y K.. Rylander 2000. A 22,000-yr Record of Monsoonal precipitation from Northern Chile's Atacama Desert. Science 289:1546-1550.

Binford, M., A. Kolata, M. Brenner, J. Janusek, M. Seddon, M. Abbott y J. Curtis 1997. Climate Variation and the Rise and Fall of an Andean Civilization. Quaternary Research 47:235-248.

Bird, J. 1943. Excavations in Northern Chile. Anthropological Papers, American Museum of Natural History 38(4). New York.

Bonavia, D. 1991. Perú. Hombre e Historia. De los Orígenes al Siglo XV . T.I. Fundación del Banco Continental para el fomento de la Educación y la Cultura. Ediciones Edubanco, Lima.

Borrero, L.W. 1996. The Pleistocene-Holocene Transition in Southern South America. En Humans at the End of the Ice Age: The Archaeology of the Pleistocene-Holocene Transition, editado por L.G. Strauss, B.V. Eriksen, J.M. Erlandson y D. Yesner, pp. 339-354. Plenum Press, New York.

Bruhns, K. O. 1994. Ancient South America. Cambridge University Press, New York.

Bruno, M.C. 2005. ¿Domesticado o silvestre? Resultados de la investigación de semillas de Chenopodium, Chiripa, Bolivia (1500-100 a.C.). Textos Antropológicos 2:39-50. Universidad Mayor de San Andrés, La Paz.

Campbell, K.E. y D. Frailey 1984. Holocene Flooding and Species diversity in Southwestern Amazonia. Quaternary Research 21:369-375.

Carré, M., L. Klaric, D. Lavallée, M. Julien, I. Bentaleb, M. Fontugne y O. Kawka 2009. Insights into Early Holocene hunter-gatherer mobility on the Peruvian Southern Coast from mollusk gathering seasonality. Journal of Archaeological Science 36:1173-1178.

Cartajena, I., L. Núñez y M. Grosjean 2007. Camelid domestication on the western slope of the Puna de Atacama, northern Chile. Anthropozoologica 42:155-173. 
Cipolla, L. 2005. Preceramic Period settlement patterns in the Huancané-Putina River Valley, Northern Titicaca Basin, Peru. En Advances in Titicaca Basin Archaeology I, editado por Ch. Stanish, A. Cohen y M. Aldenderfer, pp. 55-63. Cotsen Institute of Archaeology, University of California, Los Angeles.

Chevalier, C. 2008. Adaptaciones humanas en los Andes Centrales en el Holoceno Temprano: la contribución de los fitolitos. En Matices Interdisciplinarios en Estudios Fitolíticos y de otros Microfósiles, editado por M.A. Korstanje y M. del P. Babot, pp. 149-160. BAR International Series S1870.

Clapperton, C.M. 1993. Geology and Geomorphology of South America. Elsevier, Amsterdam.

Coben, L. y C. Stanish 2005. Archaeological reconnaissance in the Carabaya Region, Peru. En Advances in Titicaca Basin Archaeology I, editado por Ch. Stanish, A. Cohen y M. Aldenderfer, pp. 243-266. Cotsen Institute of Archaeology, University of California, Los Angeles.

Craig, N. 2005. The Formation of Early Settled Villages and the Emergence of Leadership: A Test of Three Theoretical Models in the Rio Ilave, Lake Titicaca Basin, Southern Peru. Unpublished Ph.D. Dissertation, University of California at Santa Barbara.

- - - 2011 Transiciones del Arcaico Tardío al Formativo Temprano. Una perspectiva desde la arqueología de la unidad doméstica en dos sitios del valle del Río Ilave, cuenca sur del Lago Titicaca. En Arqueología de la Cuenca del Titicaca, Perú, editado por L. Flores y H. Tantaleán. Cotsen Institute of Archaeology, University of California, Los Angeles. En prensa.

Craig, N., M. Aldenderfer, P.A. Baker y C. Rigsby 2009. Terminal Archaic Settlement Pattern and Land Cover Change in the Rio Ilave, Southwestern Lake Titicaca Basin, Peru. En The Archaeology of Anthropogenic Environments, vol. 37, editado por R. M. Dean, pp. 35-53. Center for Archaeological Investigations, Carbondale.

Craig, N. y M. Aldenderfer 2002. Domestic architecture from the Late Archaic South-Central Andean site of Jiskairumoko. Ponencia presentada en el 67th Annual Meeting of the Society for American, Denver, CO.

- - - - 2005 Trends in Early non-local obsidian artifacts from the Río Ilave viewed from surface survey and Late Archaic excavations. En Advances in Titicaca Basin Archaeology 2, editado por E. Klarich y C. Stanish. Cotsen Institute of Archaeology, University of California, Los Angeles, en prensa.

Craig, N., R.J. Speakman, R.S. Popelka-Filcoff, M. Aldenderfer, L. Flores Blanco, M. Brown, M. D. Glascock y C. Stanish 2010. Macusani obsidian from Southern Peru: A characterization of its elemental composition with a demonstration of its ancient use. Journal of Archaeological Science 37:569-576.

Cross, S.L., P. Baker, G. Seltzer y R. Dunbar 2000. A new estimate of Holocene lowstand level of Lake Titicaca, Central Andes, and implications for Tropical palaeohydrology. Holocene 10:21-32.

D’Agostino, K, G.O. Seltzer, P. Baker, S. Fritz y R. Dunbar 2002. Late Quaternary lowstand of Lake Titicaca: Evidence from HighResolution Seismic Data. Palaeogeography, Palaeoclimatology, Palaeoecology 179:97-111.
deFrance, S.D. y A. Umire 2004. Quebrada Tacahuay: Un sitio marítimo del Pleistoceno tardío en la costa sur del Perú. Chungara Revista de Antropología Chilena 36:257-278.

De Souza, P. 2004. Cazadores recolectores del Arcaico Temprano y Medio en la cuenca superior del río Loa: Sitios, conjuntos líticos y sistemas de asentamiento. Estudios Atacameños 27:7-43.

Dillehay, T.D. 2004. Monte Verde: Un Asentamiento Humano del Pleistoceno Tardío en el Sur de Chile. Lom Ediciones, Santiago.

Erickson, C.L. 1988. An Archaeological Investigation of Raised Field Agriculture in the Lake Titicaca Basin of Peru. Unpublished Ph.D. thesis, Department of Anthropology, University of Illinois, Urbana-Champaign.

Farabaugh, R. y C. Rigsby 2005. Climatic influence on sedimentology and geomorphology of the Río Ramis Valley, Peru. Journal of Sedimentary Research 75:12-28.

Flores Blanco, L., M. Aldenderfer y N. Craig 2011. Las Qochas y su relación con sitios tempranos en el valle del Ramis, cuenca norte del Titicaca. En Arqueología de la Cuenca del Titicaca, Perú, editado por L. Flores y H. Tantaleán. Cotsen Institute of Archaeology, University of California, Los Angeles. En prensa.

Flores Blanco, L., C. Cornejo, y D. Cáceda 2006. Arqueología del Norte Puneño: Sitios tardíos en Sandia y Carabaya, Perú. En Advances in Titicaca Basin Archaeology 2, editado por E. Klarich y C. Stanish. Cotsen Institute of Archaeology, University of California, Los Angeles, en prensa.

Frye, K. y E. de la Vega 2005. The Altiplano Period in the Titicaca Basin. En Advances in Titicaca Basin Archaeology 1, editado por C. Stanish, A.B. Cohen y M. Aldenderfer, pp. 173184. Cotsen Institute of Archaeology, University of California, Los Angeles.

Grosjean, M., I. Cartajena, M. A. Geyh, y L. Núñez 2003. From proxy data to paleoclimate interpretation: the Mid-Holocene paradox of the Atacama Desert, Northern Chile. Palaeogeography, Palaeoclimatology, Palaeoecology 194:247-258.

Grosjean, M., L. Núñez e I. Cartajena 2005. Palaeoindian occupation of the Atacama Desert, Northern Chile. Journal of Quaternary Science 20:643-653.

Hocsman, S. 2010. Cambios en las puntas de proyectil durante la transición de cazadores-recolectores a sociedades agro-pastoriles en Antofagasta de la Sierra (Puna Argentina). Arqueología 16:59-86. Revista del Instituto de Arqueología. Universidad de Buenos Aires.

Ibarra Grasso, D. 1957. El Paleolítico inferior en América. Cuadernos Americanos 16:135-175. México D.F.

Jackson, D., C. Méndez y P. de Souza 2004. Poblamiento Paleoindio en el norte-centro de Chile: Evidencias, problemas y perspectivas de estudio. Complutum 15:165-176.

Jennings, J. 2002. Prehistoric Imperialism and Cultural Development in the Cotahuasi Valley, Peru. Unpublished Ph.D. dissertaion, Department of Anthropology, University of California, Santa Barbara. 
Kaulicke, P. 1999. Los estudios del Período Arcaico en el Perú: Logros, problemas y propuesta. Boletín de Arqueología PUCP 3:417-436.

Keefer, D.K., S.D. deFrance, M.E. Moseley, J.B. Richardson III, D.R. Satterlee y A. Day-Lewis 1998. Early maritime economy and El Niño events at Quebrada Tacahuay, Peru. Science 281:1833-1835.

Klink, C. 2005. Archaic Period Research in the Rio Huenque Valley, Peru. En Advances in Titicaca Basin Archaeology 1, editado por Ch. Stanish, A. Cohen y M. Aldenderfer, pp. 13-24. Cotsen Institute of Archaeology, University of California, Los Angeles.

Klink, C. y M. Aldenderfer 1996. Archaic Period Settlement Patterns of the Peruvian Altiplano: A Comparison of two Recent Surveys in the Southwestern Lake Titicaca Basin. Ponencia presentada en el 24 $4^{\text {th }}$ Annual Midwest Conference of Andean and Amazonian Archaeology and Ethnohistory, Beloit, WI, USA.

- - - 2005. A projectile point chronology for the south-central Andean highlands. En Advances in Titicaca Basin Archaeology I, editado por Ch. Stanish, A. Cohen y M. Aldenderfer, pp. 25-54. Cotsen Institute of Archaeology, University of California, Los Angeles.

Lanning, E. 1963. A pre-agricultural occupation on the Central Coast of Peru. American Antiquity 27:139-154.

Lathrap, D. 1971. The tropical forest and the cultural context of Chavín. En Dumbarton Oaks Conference on Chavin, editado por E. Benson, pp. 73-100. Dumbarton Oaks, Washington DC.

- - - 1985. Jaws: The control of power in the early nuclear American ceremonial center. En Early Ceremonial Architecture in the Andes, editado por C.B. Donnan, pp. 241-267. Dumbarton Oaks, Washington DC.

Latorre, C., J.L. Betancourt, J.A. Rech, J. Quade, C. Holmgren, C. Placzek y A. Maldonado 2005. Late Quaternary History of the Atacama Desert. En $23^{\circ} \mathrm{S}$ : Archaeology and Environment of History of the Southern Deserts, editado por M. Smith y P. Hesse, pp. 73-90. National Museum of Australia, Canberra.

Lavallée, D., P. Béarez, A. Chevalier, M. Julien, P. Usselmann y M. Fontugne 1999a. Pescadores-Recolectores arcaicos del extremo sur peruano. Bulletin de l'Institut Français d'Études Andines 28:13-52.

- - - 1999b. Paleoambiente y ocupación prehistórica del litoral extremo-sur del Perú. Las ocupaciones del Arcaico en la Quebrada de los Burros y alrededores (Tacna, Perú). Boletín de Arqueología PUCP 3:393-416.

León, E. 2007. Orígenes humanos. En los Andes del Perú. Universidad de San Martín de Porres, Lima.

- - - 2009. Central Andean lithic techno-typology at the Terminal Pleistocene-Early Holocene transition. En Sourcebook of Paleolithic Transitions. Methods, Theories and Interpretations, editado por M. Camps y P. Chauhan, pp. 527-535. Springer, New York.

Le Paige, G. 1958. Antiguas culturas atacameñas en la cordillera chilena: Época paleolítica. Revista Universitaria, Año 43, Anales de la Academia Chilena de Ciencias Naturales 22:139165. Santiago.
Llagostera, A. 1977. Ocupación humana en la costa norte de Chile asociada a peces locales extintos y a litos geométricos: 9,680 +/- 160 a.p. Actas del VII Congreso de Arqueología Chilena, pp. 93-113. Ediciones Kultrún, Santiago.

- - - 1979. 9700 years of maritime subsistence on the Pacific: An Analysis by means of bioindications in the North of Chile. American Antiquity 44:309-323.

Lynch, T. 1986. Climate change and human settlement around the Late Glacial Laguna de Punta Negra, Northern Chile: The preliminary results. Geoarchaeology 1:145-161.

Marcus, J. y K. Flannery 1996. Zapotec Civilization: How Urban Society Evolved in Mexico's Oaxaca Valley. Thames and Hudson, London.

Martínez, J.G., M. Mondini, E. Pintar y M.C. Reigadas 2010. Cazadores-Recolectores tempranos de la Puna Meridional Argentina: Avances en su estudio en Antofagasta de la Sierra (Pleistoceno Final-Holoceno Temprano/Medio). Actas del XVII Congreso Nacional de Arqueología Argentina, Capítulo 32Mesa de Comunicaciones 3: Noroeste II (Tucumán, Santiago del Estero, Catamarca y La Rioja), editado por J.R. Bárcena y H. Chiavazza, Tomo IV: 1691-1696. Mendoza.

Matthews, R. 2003. The Archaeology of Mesopotamia: Theories and Approaches. Routledge, London.

McAndrews, T. 2005. Wankarani Settlement Systems in Evolutionary Perspective. Los sistemas de Asentamiento Wankarani desde una Perspectiva Evolutiva. University of Pittsburgh Memoirs in Latin American Archaeology, $\mathrm{N}^{\circ} 15$.

Mendoza, M. 2002. Band Mobility and Leadership among the Western Toba Hunter-Gatherers of Gran Chaco in Argentina. Mellen Studies in Anthropology, V. 7. Mellen Press, Lewiston, NY.

Menghin, O. y G. Schroeder 1957. Un yacimiento en Ichuña (Departamento de Puno, Perú) y las industrias Precerámicas de los Andes centrales y septentrionales. Acta Prehistórica 41-54.

Michel, M. R. 2008. Patrones de Asentamiento Precolombino del Altiplano Boliviano. Lugares Centrales de la Región de Quillacas, Departamento de Oruro, Bolivia. Tesis para optar al grado de Doctor en Filosofía. Uppsala University, Suecia.

Michel, M., P. Ayala, D. Gutiérrez, M. Beierlein, S. Calla y G. Palacios 2007. Los Chichas preinkaikos del sur de Bolivia y noroeste de la Argentina. Pacarina 4:81-96. Universidad Nacional de Jujuy.

Moraga, M., E. Aspillaga, C. Santoro, V. Standen, P. Carvallo y F. Rothhammer 2001. Análisis de ADN mitocondrial en momias del norte de Chile avala hipótesis de origen amazónico de poblaciones andinas. Revista Chilena de Historia Natural 74:719-726.

Moraga, M., P. Rocco, J.F. Miquel, F. Nervi, E. Llop, R. Chakraborty, F. Rothhammer y P. Carvallo 2000. Mitochondrial DNA polymorphisms in Chilean aboriginal populations: implications for the peopling of the Southern Cone of the Continent. American Journal of Physical Anthropology 113:19-29.

Morales, D. 1993. Historia arqueológica del Perú (del Paleolítico al Imperio Inca). Editorial Milla Batres, Lima. 
Muñoz, I., B. Arriaza, y A. Aufderheide (eds.) 1993. Acha 2 y los Orígenes del Poblamiento Humano en Arica. Ediciones Universidad de Tarapacá, Arica.

Muscio, H. J. 2001. Una revisión crítica del Arcaico Surandino. Trabajo preparado en forma original para la Cátedra Fundamentos de Prehistoria, curso año 2001. Revisión: Dra. A.M. Aguerre y Dr. J.L. Lanata. Universidad de Buenos Aires.

Núñez, L. 1983. Paleoindian and Archaic cultural periods in the arid and semiarid regions of Northern Chile. En Advances in World Archaeology, editado por F. Wendorf y A. Close, pp. 161-203. vol. 2. Academic Press, New York.

- - - 1992. Ocupación arcaica en la puna de Atacama: Secuencia, movilidad y cambio. En Prehistoria Sudamericana: Nuevas perspectivas, editado por B.J. Meggers, pp. 283-307. Taraxacum, Washington, DC.

Núñez, L. y M. Grosjean 1994. Cambios ambientales pleistocénicoholocénicos: Ocupación humana y uso de recursos en la Puna de Atacama. Estudios Atacameños 11:11-24.

Núñez, L. y C. Santoro 1988. Cazadores de la puna seca y salada del Área Centro Sur Andina (norte de Chile). Estudios Atacameños 9:13-65.

- - - 1990. Primeros pobladores en el Cono Sur de América (XII a IX milenio A.P.). Revista de Arqueología Americana 1:91-139.

Núñez, L., I. Cartajena, C. Carrasco, P. De Souza y M. Grosjean 2006. Emergencia de comunidades pastoralistas formativas en el sureste de la Puna de Atacama. Estudios Atacameños 32:93-117.

Núñez, L. M. Grosjean, B. Messerli y H. Schrelier 1997. Cambios ambientales holocénicos en la Puna de Atacama y sus implicancias paleoclimáticas. Estudios Atacameños 12:25-33.

Núñez, L. M. Grosjean e I. Cartajena 1999. Un ecorrefugio oportunístico en la Puna de Atacama durante eventos áridos del Holoceno Medio. Estudios Atacameños 17:125-174.

- - - 2001 Human dimensions of Late Pleistocene/Holocene arid events in Southern South America. En Interhemispheric Climate Linkages, editado por V. Markgraf, pp. 105-117. Academic Press: San Diego.

- - - 2002. Human occupations and climate change in the Puna de Atacama, Chile. Science 298:821-824.

Olivera, D.E. 2001. Sociedades agropastoriles tempranas: El Formativo inferior del Noroeste Argentino. En Historia Argentina Prehispánica, Tomo I, pp. 83-125. Brujas, Córdoba.

Olivera, D. y P. Tchilinguirian 2006. Humedales de altura y capacidad de sustentación para camélidos (Antofagasta de la Sierra, Catamarca, Argentina). Presentado en el IV Congreso Mundial sobre Camélidos. Santa María, Catamarca.

Olivera, D.E., P. Tchilinguirian y M.J. de Aguirre 2006. Cultural and environmental evolution in the meridional sector of the Puna of Atacama during the Holocene. En Change in the Andes: Origins of Social Complexity, Pastoralism and Agriculture, coordinado por H. Yacobaccio y D. Olivera. BAR International Series 1524, Oxford.

Oliveto, G. y B. Ventura 2009. Dinámicas poblacionales de los valles orientales del sur de Bolivia y norte de Argentina, siglos
XV-XVII. Aportes etnohistóricos y arqueológicos. Población y Sociedad 16:119-150.

Palao Berastain, J. 1989. Precerámico de Chucuito. Boletín del Instituto de Estudios Aymaras. Puno.

Palacios Ríos, F. 1984. El taller lítico de Tumuku. Revista del Museo del Instituto de Arqueología 23:15-36. Cuzco.

Patterson, T.C. y R. Heizer. 1965. A Preceramic Stone Tool Collection from Viscachani, Bolivia. Nawpa Pacha 3:107-115. Institute of Andean Studies, Berkeley.

Perry, L., D. Sandweiss, D. Piperno, K. Rademaker, M. Malpass, A. Umire y P. de la Vera 2006. Early Maize Agricultura and Interzonal Interaction in Southern Peru. Nature 440:76-79.

Perry, L., R. Dickau, S. Zarrillo, I. Holst, D.M. Pearsall, D.R. Piperno, M.J. Berman, R.G. Cooke, K. Rademaker, A.J. Ranere, J. Scott Raymond, D.H. Sandweiss, F. Scaramelli, K. Tarble y J.A. Zeidler 2007. Starch fossils and the domestication and dispersal of chili peppers (Capsicum spp. L.) in the Americas. Science 315:986-988.

Piu Salazar, P. 1977. Quellkata: Un Sitio Arqueológico el Distrito de Mazo Cruz, Provincia de Chuquito. Tesis para optar al Grado de Bachiller en Historia y Antropología. Universidad Nacional de San Agustín. Arequipa, Perú.

Politis, G. 1991. Fishtail projectile points in the Southern Cone of South America: An overview. En Clovis: Origins and Adaptations, editado por R. Bonnichsen y K. Turnmire, pp. 287-301. Center for the Study of the First Americans, Orono, Maine.

Politis, G., P.G. Messineo y C.A. Kaufmann 2004. El poblamiento temprano de las llanuras pampeanas de Argentina y Uruguay. Complutum 15:207-224.

Quade, J., J.A. Rech, J.L. Betancourt, C. Latorre, B. Quade, K.A. Rylander y T. Fisher 2008. Paleowetlands and Regional Climate Change in the Central Atacama Desert, northern Chile. Quaternary Research 69:343-360.

Rademaker, K. 2006. Geoarchaeological Investigations of the Wayñuña site and the Alca Obsidian Source, Peru. Tesis para optar al grado de Master en Ciencias, Universidad de Maine.

Ray, N. y R. Adams 2001. A GIS-based vegetation map of the world at the Last Glacial Maximum (25,000-15,000 BP). Internet Archaeology 11. (http://intarch.ac.uk/journal/issue11/ rayadams_toc.html) (1 de abril 2010).

Rech, J., J. Quade y J.L. Betancourt 2002. Late Quaternary paleohydrology of the Central Atacama Desert (lat $22^{\circ}-24^{\circ} \mathrm{S}$ ), Chile. GSA Bulletin 114(3):334-348.

Rick, J. 1980. Prehistoric Hunters of the High Andes. Academic Press, New York.

Rigsby, C., R. Farabaugh y P. Baker 2002. Quaternary Sedimentary and Geomorphic History of River Valleys in the Lake Titicaca Basin, Peru and Bolivia. EOS Transactions, AGU 83(47), Fall Meet. Supplement, Abstract GC21B-0154.

Rigsby, C., P. Baker y M. Aldenderfer 2003. Fluvial history and human occupation of the Rio Ilave Valley, Peru. Palaeogeography, Palaeoclimatology, and Palaeoecology 194:281-297.

Rivera, C. 2004. Regional Settlement Patterns and Political Complexity in the Cinti Valley, Bolivia. Tesis para optar al grado de Doctor en Filosofía. Universidad de Pittsburgh, Pittsburgh. 
Rivera, C. y M. Strecker 2005. Arqueología y arte rupestre de Bolivia. Introducción y bibliografía. Ibero-Amerikanisches Institut Preußischer Kulturbesitz, Berlín.

Rivera, M. 1975. Una hipótesis sobre movimientos poblacionales altiplánicos y transaltiplánicos a las costas del Norte de Chile. Chungara 5:7-31.

Rivera, M.A. y F. Rothhammer 1986. Evaluación biológica y cultural de poblaciones Chinchorro: nuevos elementos para la hipótesis de contactos transaltiplánicos, cuenca Amazonas-Costa Pacífico. Chungara 16-17:295-306.

Rivero, D.E. y E.E. Berberián 2008. El poblamiento de la región central del territorio argentino durante la transición PleistocenoHoloceno (12.000-9.000 a.p.). Revista Española de Antropología Americana 38(2):17-37.

Román, N. y S. Román 2011. Prácticas funerarias de los períodos Altiplano/Inca en el valle de Ollachea, Carabaya. En Arqueología de la Cuenca del Titicaca, Perú, editado por L. Flores y H. Tantaleán. Cotsen Institute of Archaelology, University of California, Los Angeles. En prensa.

Roosevelt, A. C., M. Lima da Costa, C. Lopes Machado, M. Michab, N. Mercier, H. Valladas, J. Feathers, W. Barnett, M. Imazio da Silveira, A. Henderson, J. Sliva, B. Chernoff, D.S. Reese, J.A. Holman, N. Toth y K. Schick 1996. Paleoindian Cave dwellers in the Amazon: The peopling of the Americas. Science 272:373-384.

Rothhammer, F. y T.D. Dillehay 2009. The Late Pleistocene colonization of South America: An interdisciplinary perspective. Annals of Human Genetics 73:540-549.

Rothhammer, F., C. Santoro, E. Poulin, B. Arriaza, M. Moraga, y V. Standen 2009. Archeological and mtDNA evidence for tropical lowland migrations during the Late Archaic/Formative in northern Chile. Revista Chilena de Historia Natural 82:543-552.

Rothhammer, F., C. Silva, J.A. Cocilovo y S. Quevedo 1986. Una hipótesis provisional sobre el poblamiento de Chile basada en el análisis multivariado de medidas craneométricas. Chungara 16-17:115-118.

Rothhammer, F. y C. Silva 1992. Gene geography of South America: Testing models of population displacement based on archeological evidence. American Journal of Physical Anthropology 89:441-446.

Rumold, C. 2010. Women's Work and the Advent of Agriculture in the Titicaca Basin of Southern Peru: Illuminations from Microbotanical Starch and Grinding Tool Analyses. Unpublished Ph.D. Dissertation, University of California, Santa Barbara.

Sandweiss, D. 2003. Terminal Pleistocene through Mid-Holocene archaeological sites as paleoclimatic archives for the Peruvian Coast. Palaeogeography, Palaeoclimatology, Palaeoecology 194:23-40.

Sandweiss, D.H., H. McInnis, R.L. Burger, A. Cano, B. Ojeda, R. Paredes, M. Sandweiss y M. Glascock 1998. Quebrada Jaguay: Early South American maritime adaptations. Science 281:1830-1832.

Santoro, C. 1989. Antiguos Cazadores de la Puna (9.000 a 6.000 A.C.). En Culturas de Chile, Prehistoria desde sus Orígenes hasta los Albores de la Conquista, editado por J. Hidalgo,
V. Schiappacasse, H. Niemeyer, C. Aldunate e I. Solimano, pp. 33-56. Editorial Andrés Bello, Santiago.

Santoro, C. y C. Latorre 2009. Propuesta metodológica interdisciplinaria para poblamientos humanos Pleistoceno tardío/ Holoceno temprano, precordillera de Arica, Desierto de Atacama Norte. Andes 7:13-35.

Santoro, C. y L. Núñez 1987. Hunters of the Dry Puna and Salt Puna in Northern Chile. Andean Past 1:57-110.

Spooner, D.M., K. McLean, G. Ramsay, R. Waugh y G.J. Bryan 2005. A Single domestication for potato based on multilocus amplified fragment length polymorphism genotyping. Proceedings of the National Academy of Sciences 102(41):14694-14699.

Smith, B. 2001. Low level food production. Journal of Archaeological Research 9:1-43.

Standen, V., C. Santoro y B. Arriaza 2004. Síntesis y propuesta para el Período Arcaico en la costa del extremo Norte de Chile. Chungara Revista de Antropología Chilena 36, número especial, Tomo 1, pp. 201-212.

Stanish, C. 2003. Ancient Titicaca: The Evolution of Complex Society in Southern Peru and Northern Bolivia. University of California Press, Berkeley.

Stanish, C., R. Burger, L. Cipolla, M. Glascock, y E. Quelima 2002. Evidence for Early long-distance obsidian exchange and watercraft use from the Southern Lake Titicaca basin of Bolivia and Peru. Latin American Antiquity 13:444-454.

Stanish, C., E. de la Vega, L. Steadman, C. Chávez Justo, K. Frye, L. Onofre Mamani, M. Seddon y P. Calisaya Chuquimia 1997. Archaeological Survey in the Juli-Desaguadero Region of Lake Titicaca Basin, Southern Peru. Volume 29 of Fieldiana Anthropology, Field Museum of Natural History, Chicago.

Stanish, C. y A. Plourde 2000. Formative Period settlement patterning in the Huancane-Putina River Valley, northeastern Titicaca Basin. Ponencia presentada en el $66^{\text {th }}$ Annual Meeting of the Society for American Archaeology, New Orleans, Louisiana.

Stanish, C. y A. Umire 2002. Prospección arqueológica del Sector Bajo de la Cuenca del Ramis (Ríos Azangaro y Ramis), Puno. Reporte Final enviado al Instituto Nacional de Cultura, Lima.

Szykulski, J. 2010. Nuevas evidencias del período precerámico en el sur del Perú. Conjunto arqueológico de Churajón. Manuscrito en posición del autor.

Tello, J.C. 1942. Origen y desarrollo de las civilizaciones prehispánicas Andinas. Reimpreso de las actas del XXVII Congreso de Americanistas de 1929, Lima.

Thompson, L.G., M.E. Davis, E. Mosley-Thompson, T.A. Sowers, K.A. Henderson, V.S. Zagorodnov, P.-N. Lin, V.N. Mikhalenko, R.K. Campen, J.F. Bolzan, J. Cole-Dai y B. Francou 1998. A 25,000-Year Tropical climate history from Bolivian ice cores. Science 282:1858-1864.

Tripcevich, N. 2002. Viewshed Analysis of the Ilave River Valley. M.A. Thesis, Department of Anthropology, University of California, Santa Barbara.

Willey, G. 1988. Junius Bouston Bird and American archaeology. En Travels and Archaeology in South Chile by Junius B. Bird, editado por J. Hyslop, pp. xiii-xxxi. University of Iowa Press, Iowa City. 
Wise, K. 1997. The Late Archaic Period Occupation at Carrizal, Peru. Contributions in Science 467:1-16. Natural History Museum of Los Angeles County.

- - - 1999. Kilómetro 4 y la ocupación del Período Arcaico en el área de Ilo, al sur del Perú. Boletín de Arqueología PUCP 3:335-363.

Uhle, F.M. 1919. La arqueología de Arica y Tacna. Boletín de la Sociedad Ecuatoriana de Estudios Americanos 7-8. Quito.

- - - 1922. Fundamentos Étnicos y Arqueología de Arica y Tacna. Sociedad Ecuatoriana de Estudios Históricos Americanos, Quito.

Usselmann, P., M. Fontugne, D. Lavallée, M. Julien y C. Hatté 1999. Estabilidad y rupturas dinámicas en el Holoceno de la costa surperuana: el valle de la quebrada de Los Burros (departamento de Tacna). Bulletin de l'Institut Français d'Études Andines 28:1-11.

Ventura, B., P. Delcourt, G. Ortiz, L. Methfessel, C. Greco, W. Buitrago y F. Paredes 2010. El registro arqueológico de las antiguas poblaciones de los valles orientales de la Provincia Arce, Tarija, Bolivia. Intersecciones en Antropología 11:59-72.

Yacobaccio, H.D. 2003. Procesos de intensificación y de domesticación de camélidos en los Andes centro-sur. En Memorias del Tercer Congreso Mundial sobre Camélidos. Tomo I: 211216. Potosí.

\section{Notas}

1 Se ha sugerido que las cuentas de oro de un contexto funerario del Arcaico Final en Jiskairumoko, Ilave, (ca. cuatro mil años de edad), podrían provenir del flanco oriental (Aldenderfer et al. 2008: 5004). Es una suposición muy lógica si tomamos en cuenta que las minas de los actuales departamentos de Carabaya y Sandia fueron muy valiosas en tiempos prehispánicos tardíos y durante la colonia (Flores et al. 2006). Además recientemente hemos dado a conocer el uso, poco frecuente, de un tipo de obsidiana atípica-Macusanita- que proviene de la cordillera oriental de Carabaya, la cual se ha utilizado para tallar puntas de proyectil usadas, sobre todo, en el norte de la cuenca del Titicaca (Craig et al. 2010).

2 Durante el Horizonte Medio se utilizaron con frecuencia varios alucinógenos amazónicos (por ejemplo, el cebil) en el altiplano (Aldenderfer 2010).
3 Se ha reportado el procesamiento de una especie de Marantaceae llamada arrurruz en la sierra occidental de Arequipa durante el Arcaico Tardío del sitio Waynuña (Perry et al. 2006); es una hierba amazónica usada como alimento, remedio, e incluso para uso legendario como antídoto para las toxinas de flechas con punta venenosa.

4 Tal cronología fue común en los Andes en estos tiempos y estuvo basada primordialmente sobre las formas de puntas de proyectil o tecnología de instrumentos reducidos. En algunos casos, como la famosa secuencia Ancón-Chillón de la costa central del Perú (Lanning 1963; Kaulicke 1999:418), formas de instrumentos de contextos de superficie fueron usadas como tipos fósiles, al igual que puntas de contextos excavados y estratificados. 